\title{
Modeling Irrigation Networks for the Quantification of Potential Energy Recovering: A Case Study
}

\author{
Modesto Pérez-Sánchez ${ }^{1}$, Francisco Javier Sánchez-Romero ${ }^{2}$, Helena M. Ramos ${ }^{3}$ \\ and P. Amparo López-Jiménez ${ }^{1, *}$ \\ 1 Hydraulic and Environmental Engineering Department, Universitat Politècnica de València, Valencia 46022, \\ Spain; mopesan1@upv.es \\ 2 Rural and Agrifood Engineering Department, Universitat Politècnica de València, Valencia 46022, Spain; \\ fcosanro@agf.upv.es \\ 3 Civil Engineering, Architecture and Georesources Departament, CERIS, Instituto Superior Técnico, \\ Universidade de Lisboa, Lisboa 1049-001, Portugal; hramos.ist@gmail.com \\ * Correspondence: palopez@upv.es; Tel.: +34-96-387700 (ext. 86106)
}

Academic Editor: Ashok K. Chapagain

Received: 29 February 2016; Accepted: 26 May 2016; Published: 1 June 2016

\begin{abstract}
Water irrigation systems are required to provide adequate pressure levels in any sort of network. Quite frequently, this requirement is achieved by using pressure reducing valves (PRVs). Nevertheless, the possibility of using hydraulic machines to recover energy instead of PRVs could reduce the energy footprint of the whole system. In this research, a new methodology is proposed to help water managers quantify the potential energy recovering of an irrigation water network with adequate conditions of topographies distribution. EPANET has been used to create a model based on probabilities of irrigation and flow distribution in real networks. Knowledge of the flows and pressures in the network is necessary to perform an analysis of economic viability. Using the proposed methodology, a case study has been analyzed in a typical Mediterranean region and the potential available energy has been estimated. The study quantifies the theoretical energy recoverable if hydraulic machines were installed in the network. Particularly, the maximum energy potentially recovered in the system has been estimated up to $188.23 \mathrm{MWh} /$ year) with a potential saving of non-renewable energy resources (coal and gas) of $\mathrm{CO}_{2} 137.4 \mathrm{t} /$ year.
\end{abstract}

Keywords: smart water; water-energy nexus; energy efficiency; sustainable water management; energy recovering

\section{Introduction}

Water and its management is one of the more important current and future global challenges. Its variability can cause cloudbursts, making sewers to overflow, while the scarcity of water in other components involves public services and reduces irrigation [1]. Hence, an efficient management of water irrigation networks is crucial for facing future challenges related to the energy-water nexus, considering the importance of irrigation in the whole planet [2]. The development of the modernization of irrigation systems in agriculture (replacing open channel with pressurized irrigation) has considerably increased energy consumption in recent years [3]. Nevertheless, the establishment of drip irrigation has made more efficient systems in water consumption but not in energy demand.

Spain is not an exception: The annual irrigation volume consumed in Spain is $16.344 \mathrm{~km}^{3} /$ year [4] and the global irrigation consumption in pressure systems approaches $3925 \mathrm{~km}^{3} /$ year [5]. Consequently, the theoretical energy recoverable could be a significant amount.

In Spain, the drip irrigated area (i.e., 1.7 of 3.54 million of hectares are irrigated by pressure systems) [6] represents $17.56 \%$ of the world's surface irrigated by localized drip (approximately 
9 million hectares) [7]. The high energy consumption and the rising cost of tariff have reduced profits or even the viability of farms [8]. The need to study strategies to decrease the energy consumption in these installations is pointed out in the consulted references. Regarding this issue, Coehlo et al. established the need to study the recovery in water distribution systems for increasing the energy efficiency, since the energy consumption in water networks involves $7 \%$ of the global energy consumption [9]. The objectives of this recovery are: to reduce the energy footprint of water in irrigation system and to lessen greenhouse emissions compared with other non-renewable energy sources.

Water-energy nexus analysis has become a crucial issue in recent years [3,10-13]. Baki et al. [10] studied water-energy interactions in water systems in Athens. Okadera et al. [11] and Herath et al. [12] analyzed water footprints of hydroelectricity. Water management improvement in irrigation networks have also been analyzed in [14], where a 40\% irrigation reduction volume was achieved.

Sustainable social and economic growth based on renewable energy sources forces water networks to work as multipurpose systems [15], where power generation is not the first objective but an important complementary one [16].

Some studies and prototypes of recovering energy with small turbines can be found in the literature for power less than $100 \mathrm{~kW}$ [17-22]. The previous publications of Carravetta et al. [17,18] compare the feasible regulation systems for pump as turbines (PATs). These authors [19,20] determined performance of PATs installed in drinking systems. The efficiency oscillates between 0.4 and 0.6. Ramos et al. [21,22] proposed new design solutions to energy production in water pipe systems. These solutions are focused on the installing of PATs with electrical or hydraulic regulation within network. Additionally, to the previous referenced authors, the variability of the flow along time is studied as an objective in the present research. Here, a deep analysis of theoretical recovery energy in the network is proposed (i.e., distinguishing values of dissipated energy, necessary energy and losses in lines and consumption points).

Particularly in irrigation networks, some studies of recovering energy in open channels flow [23-25] and preliminary studies in pressure pipe systems are described. These show the importance to analyze these networks in terms of recovery energy. An example of these studies is the network of Alqueva in Portugal [26]. In that contribution, authors analyzed the recovery energy with average steady state flows. A discretized analysis in short time intervals is proposed for determining the theoretical energy recoverable in a part of the Alqueva distribution network. This analysis was made with average consumption demands.

The present research determines the variability of flows and pressure in any point or line on the network depending on irrigation habits. This advantage (determining instant values of flows and pressure) allows performing the analysis of energy recovery in any point on the network. The methodology obtains the data pairs of flow $(\mathrm{Q})$ and head $(\mathrm{H})$ of the working area of the hypothetical installed machine.

Furthermore, the methodology determines the variation of flow in a network based on the habits of irrigation in order to perform energy analyses. The application of this methodology in irrigation networks aims to complement previous studies for PATs efficiency in dinking supply networks, extending its use.

The variation of flow is based on random demand of the users and the real irrigation allocations. Depending on these parameters, the proposed methodology estimates the energy dissipated by friction losses, the energy required for irrigation, and the recoverable energy in the irrigation network. The discretization of the flows leads managers to analyze power generation depending on irrigation time periods. Accordingly, the present analysis has the following objectives:

1) Proposing a new methodology for determining the flows throughout the year in an irrigation network demand, considering the need of the crop, the historic consumption and the irrigation farmers' habits

2) Estimating the flow rate and pressures with the time 
3) Quantifying the energy balance in pressurized irrigation distribution systems to determine the energy footprint of water in the distribution system, and the estimated recoverable energy

4) Applying these procedures to a real case study

\section{Methods and Materials}

\subsection{Methodology for Determining the Flow}

In this section, the proposed methodology to determine the time-dependent flow throughout the year is described. In order to analyze any pressurized irrigation network from the energy point of view, the flow and pressure along pipelines are determinant variables. The requirements of the minimum pressure at any consumption point are also fundamental. Pressures are different depending on the location of irrigation points. Therefore, the spatial and timing distribution of these consumptions are important aspects to take into consideration.

The flows are variable over any irrigation campaign, depending on many factors such as distribution of crops in the irrigation area, crop maturity, weather conditions, soil characteristics, efficiency of drippers (ranging from 0.90 to 0.95 ), and the habits of farmers, among others.

Traditionally, the Clement methodology has been used for irrigation network sizing [27-29]. This methodology allows determining the maximum flow circulating in a network line. This maximum flow rate is calculated by assuming a binomial distribution flow. The mathematical expectation and standard deviation of the binomial probability distribution depends on the opening point of consumption. Clement assumed that this probability was uniform and equal over time. This uniform probability consideration can lead to underestimating the flows. Consequently, the Clement methodology cannot be used for analyzing potential energy recovery. Probability of irrigation at any point is non-uniform, and depends on the habits of irrigation farmers. Therefore, it varies throughout the day, week, and month. This underestimation leads to the proposal of different methodologies for estimating flows in irrigation networks. The most common are those that use statistical methods [27-29], or models based on the random opening of irrigation points by means of computer simulations [30-33]. A new methodology considering both strategies is here proposed.

Flow and energy implications are therefore separately considered and described.

The majority of water distribution networks only have water meters in each irrigation point for billing and controlling the consumed volumes. Unfortunately, it is not usual that the irrigation network has readings of flows and pressures at any time. For this reason, the proposed methodology simulates the operation of any irrigation network based on the random generation of consumption in irrigation points.

The day, start, and duration of irrigations (as function of the habits of the farmers) are considered in this research as factors for irrigation probability and flows. Furthermore, the real consumption probability weights (obtained from historical archives of the irrigation entities) can be assigned to consumptions, and the network can be very precisely simulated.

Hence, for any day of the year, consumptions can be estimated in any irrigation point by following these steps (Figure 1).

1. Estimation of cumulative volume consumed by the irrigation point

The decision to irrigate depends on the balance $\left(\mathrm{V}_{\mathrm{Na}}\right)$ between the previous irrigated volume and the consumption assigned (needs) of the irrigation point (Input 1). If the volume of cumulative consumption is positive, automatically the methodology indicates that this is not an irrigation day. Only when this volume is negative, irrigation is possible. If the volume of cumulative consumption is negative, the methodology determines the irrigation probability.

2. The determination of the irrigation probability $\left(\mathrm{P}_{\mathrm{I}}\right)$ 
To randomly determine if crops are irrigated or not during a particular day, two types of weight functions are assigned. These functions are obtained from interviews with farmers. According to Figure 1, Input 2 determines the irrigation weekly pattern $\left(w_{d j}\right)$, prioritizing the irrigation days per week. Input 3 determines the maximum days between irrigations for each month of the year $(i)$. If in previous days no irrigation has been performed, watering is forced.

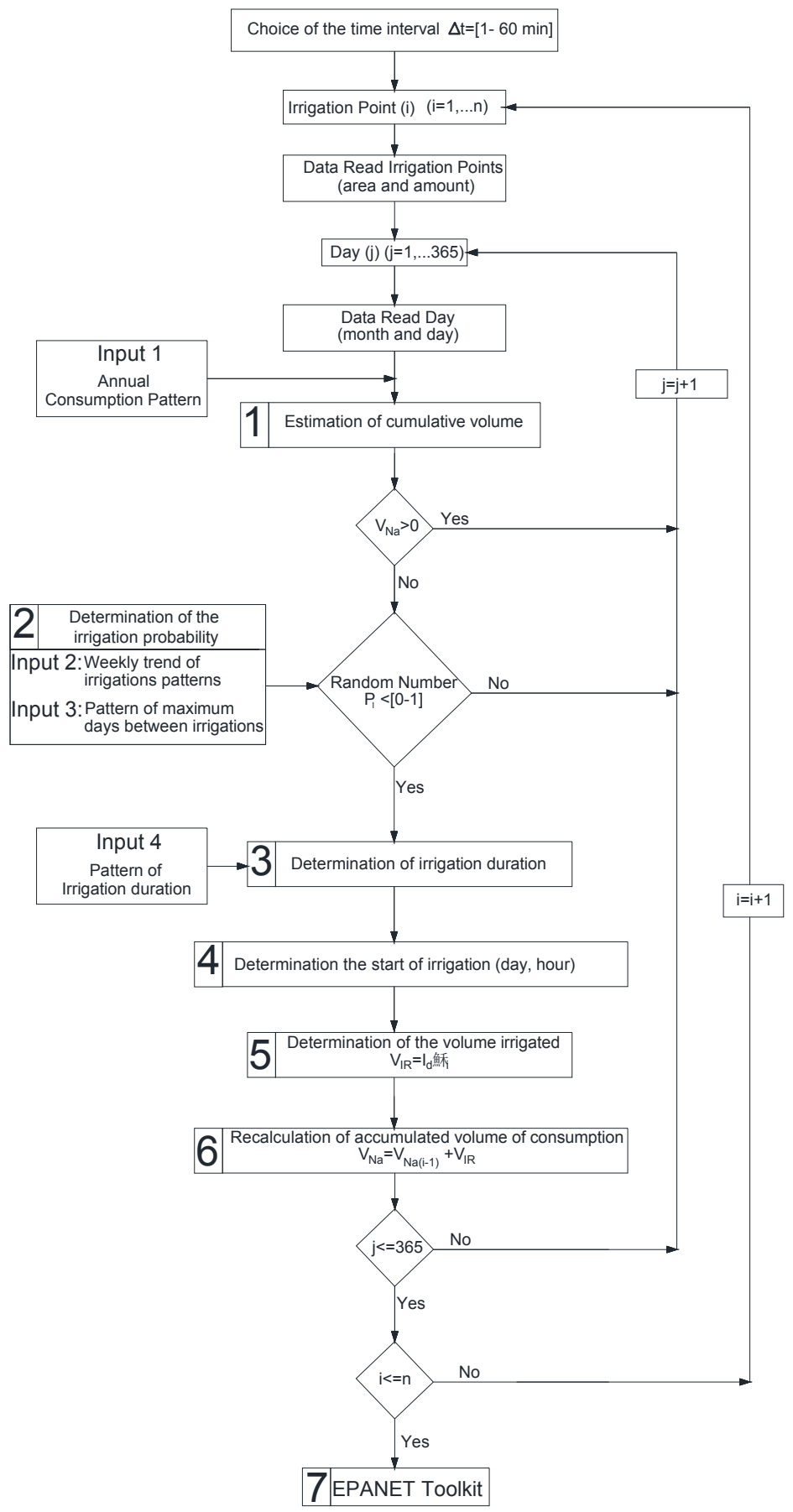

Figure 1. Schematic description of the methodology for flow estimation.

The methodology generates a random number $(R N)$ between zero and one associated with an irrigation probability. If $R N_{j} \leqslant \mathrm{P}_{I}$ irrigation is assigned to this consumption point.

$$
\mathrm{P}_{I}=\frac{w_{d j}}{\sum_{n=1}^{n=i-j+1} w_{d n}}
$$


where:

$i=$ numbers of days inside of interval;

$j=$ day of decision making;

$w_{d j}=$ pattern to irrigate one particular day inside the interval;

$\sum_{n=1}^{n=i-j+1} w_{d n}=$ total addition of patterns.

3. The determination of the irrigation duration

The methodology allows determining the estimated time based on irrigation habits of farmers to satisfy irrigation needs (Input 1). This value depends on irrigation amount and type of crop.

4. The start of irrigation

The irrigation duration randomly determines the start of irrigation as a function of the daily probability curves of irrigation time (Input 4). When the methodology determines that a consumption point has to be irrigated, the start time of irrigation is determined. Therefore, the cumulative probability must be used for starting irrigation. This curve is defined by twenty-four sections (one per hour). When no irrigation exists, the irrigate weight $\left(w_{h}\right)$ in this interval is assigned to be zero.

The probability in the time interval $\left(p_{h}\right)$ is:

$$
p_{h}=\frac{w_{h}}{\sum_{h=0}^{h=23} w_{h}}
$$

where $w_{h}$ is the defined pattern (Input 2) to irrigate one particular hour inside the interval.

The cumulative probability $\left(p_{c m}\right)$ is:

$$
p_{c}=\sum_{h=0}^{h=m} p_{h}(m=0, \ldots, 23)
$$

where $m$ is the number of intervals in one day.

A new $R N$ is generated, ranging from 0 to 1 . It is compared with the values of cumulative probability $\left(p_{c m}\right)$ and the start irrigation period is established. For this particular time period, the methodology selects within this period the start interval from zero to value equal to $\frac{60}{\Delta t}$ (where $\Delta t$ is the time interval in which the simulated flow is discretized). When this step is completed, the day and hour of starting irrigation is known.

5. Determination of irrigation volume

The irrigation supply (agronomic known parameter, which depends on: framework plantation, number of dripper per plant and flow of the dripper) and the duration (Input 4) are known and the irrigation volume can be calculated for that day.

6. Calculation of cumulative consumption

When the irrigation volume is known, the methodology updates the water volume available for the plant.

7. The pressure and flow modeled for each node in the network

They are calculated for every irrigation points and each day using Epanet Toolkit. Epanet is public domain software [34] that models water distribution in pipe systems. Different elements can be represented: pipe networks composed by pipes, nodes (junctions), pumps, valves, and storage tanks or reservoirs. The model can simulate extended-period hydraulic analysis by simulating by sort of pipes systems, computing friction and minor losses, representing various types of valves, junctions, tanks and pumps, considering multiple patterns at nodes consumption with time variation, and system operation on simple tank level, timer controls or complex rule-based controls. 


\subsection{Balance of Energy}

Once flows and pressures are estimated along the time in the whole network, the energy equation (Reynolds Theorem) must be implemented to consider the energy balance in the system [35].

According to Figure 2, a generic irrigation network with all possible elements (reservoir, pumps, turbines, and compensation tanks) is presented. The conservation of energy equation is defined as:

$$
\frac{d E}{d t}=\frac{d Q}{d t}+\frac{W_{\text {shaft }}}{d t}=\frac{d}{d t} \iiint_{C V} \rho\left(g z+u+\frac{v^{2}}{2}\right) d V+\iint_{C S}\left(g z+u+\frac{P}{\rho}+\frac{v^{2}}{2}\right) \rho(\vec{v} \cdot d \vec{A})
$$

where:

$\frac{d E}{d t}=$ exchange of energy per unit time in the control system;

$\frac{d Q}{d t}=$ exchange of heat per unit of time (heat power);

$\frac{W_{\text {shaft }}}{d t}=$ power transmitted directly to or from the fluid (e.g., pump);

$\mathrm{dV}=$ differential volume of control volume for integration;

$\vec{v}=$ velocity vector of fluid;

$d \vec{A}=$ differential area of control surface for integration;

$\rho=$ fluid density;

$g z=$ potential energy per unit mass;

$u=$ internal energy per unit mass;

$\frac{v^{2}}{2}=$ kinetic energy per unit mass;

$\frac{P}{\rho}=$ height of pressure per unit mass;

Within the control system, the following simplifications can be made:

The water density is constant.

Flow is uniform in each interval.

Exchange of heat between fluid and surroundings is negligible (adiabatic system).

The shaft work is the power transmitted directly to/from the fluid in the case that a pump or turbine exists in the network.

There is no compensation tank in the network, therefore, the time energy variation inside of the control volume as function of time is negligible.

\section{Pressure Water System (PWS) Control Volume (CV)}

Water Network CV

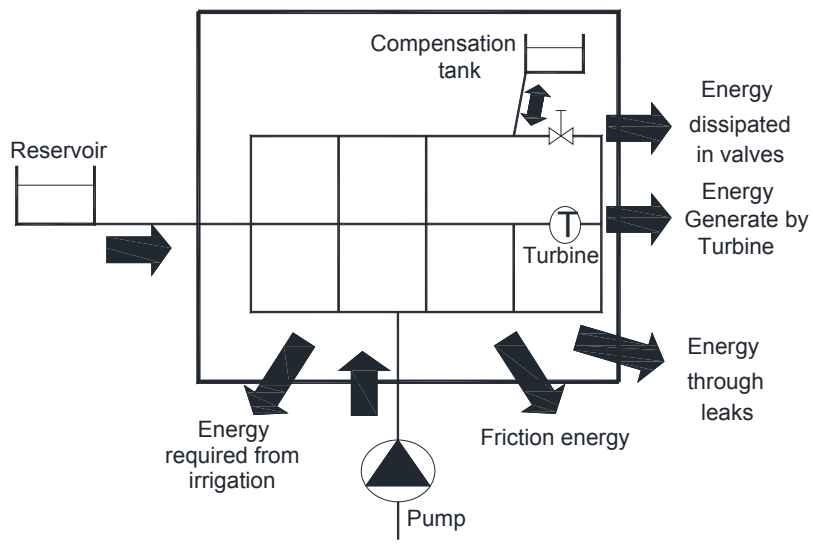

Figure 2. Energy balance in the pressurized irrigation water network adapted from [36]. 
If an irrigation system operates by gravity (Figure 3), the equation of energy applied to any control system along a time interval is defined by Equation (5):

$$
\gamma Q_{D} H_{D} \Delta t=\sum_{i=1}^{n} \gamma Q_{o i} H_{o i} \Delta t+\rho\left(\sum_{i=1}^{n}\left(Q_{o i} u_{o i}-Q_{D i} u_{D i}\right)\right) \Delta t
$$

where:

$\Delta t=$ time interval (s);

$n=$ total number of irrigation points;

$i=$ individual irrigation points;

$\gamma=$ specific weight of the fluid $\left(\mathrm{N} / \mathrm{m}^{3}\right)$;

$Q_{D}=$ total flow demanded by the network $\left(\mathrm{m}^{3} / \mathrm{s}\right)$;

$H_{D}=$ piezometric head of the reservoir. For a pumped system, the value is the manometric height;

$Q_{o i}=$ flow demanded by each irrigation point $\left(\mathrm{m}^{3} / \mathrm{s}\right)$;

$H_{o i}=$ piezometric head of the consumption node (m);

$\gamma Q_{D} H_{D}=$ total energy $(\mathrm{kW})$ supplied to the system. This term is equal to $E_{T}$, which is later defined;

$\sum_{i=1}^{n} \gamma Q_{o i} H_{o i}=$ energy consumed by all irrigation points $(\mathrm{kW})$. This term will be defined as $E_{R I}$ plus $E_{T R I}$;

$\rho\left(\sum_{i=1}^{n}\left(Q_{o i} u_{o i}-Q_{D i} u_{D i}\right)\right)=$ Exchange of internal energy. In an adiabatic system, it is equal to friction losses. This term will be defined as $E_{F R}$.

Leakages are not considered in this analysis because the drip irrigation network is still new (minimum leakages), the maintenance and repair plans are usually undertaken (which reduce possible losses), and finally, these networks are not as automated as drinking systems so unmeasured volumes and leakages are difficult to discern. If an energy audit were made, this volume should be considered or estimated [6,36]. Furthermore, the installation of hydraulic machines does not affect the water quality of the final use (i.e., irrigation).

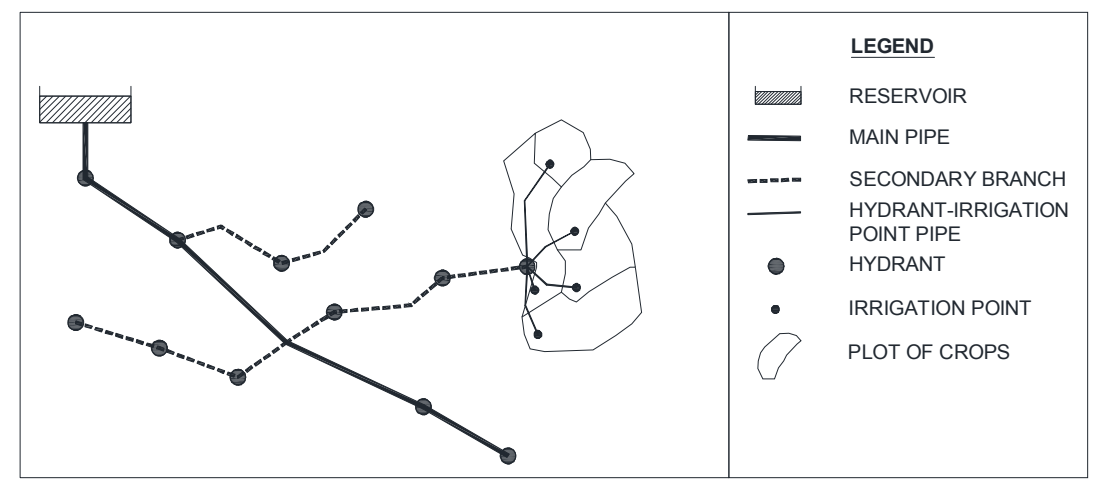

Figure 3. Scheme of irrigation network.

When a global energy balance of the network is established, it is possible to define different terms of energy. Such as lines, hydrants and irrigation points, as follow (Figure 4):

- Total Energy $\left(E_{T i}\right)$ : potential total energy in an irrigation point when the consumption is null in the entire network. It corresponds to the static energy (i.e., potential) of the node. For an irrigation point along a time interval, the value is:

$$
E_{T_{i}}(k W h)=\frac{9.81}{3600} Q_{i}\left(z_{o}-z_{i}\right) \Delta t
$$


where:

$Q_{i}$ is the flow circulating by a line that supplies to more unfavorable irrigation point (most disadvantageous consumption node in terms of need of the pressure) $\left(\mathrm{m}^{3} / \mathrm{s}\right)$;

$z_{i}$ is the geometry level above reference plane of the irrigation point. In this case, the reference is sea level (m);

$z_{0}$ is the geometry level above reference plane of the free water surface of the reservoir. In this case, the reference is sea level $(\mathrm{m})$;

$\Delta t$ is the time interval (s).

- Friction Energy $\left(E_{F R i}\right)$ : for a time interval, it is the energy dissipated in the network by the water coming from head until the irrigation point.

$$
E_{F R_{i}}(k W h)=2.725 \cdot 10^{-3} Q_{i}\left(z_{o}-\left(z_{i}+P_{i}\right)\right) \Delta t
$$

where:

$P_{i}$ is the service pressure in any point of the network when consumption exists. The units are meter water column (m w.c.).

Minor losses (pressure loss in particular network components like tees, valves, and similar) are considered as a percentage of friction losses. Associated with this term, the Energy Footprint of Water (EFW) can be calculated. Energy Footprint of Water is defined as the ration between energy dissipated due to friction losses $\left(E_{F R i}\right)$ over the distributed volume on the network $\left(\mathrm{kWh} / \mathrm{m}^{3}\right)$.

- $\quad$ Theoretical Energy Necessary $\left(E_{T N i}\right)$ : it is the minimum energy required in a hydrant or line to ensure the minimum pressure of irrigation in the more unfavorable point. The value is:

$$
E_{T N_{i}}(k W h)=2.725 \cdot 10^{-3} Q_{i} P_{\min _{i}} \Delta t
$$

where:

$P_{\min _{i}}$ is the minimum pressure of service of a line or hydrant to ensure the minimum pressure in the most disadvantageous consumption node. The units are meter water column (m w.c.).

- Energy Required for Irrigation $\left(E_{R I}\right)$ : during an interval of time, it is the minimum energy required at an irrigation point to ensure the irrigation water evenly. The value is:

$$
E_{R I_{i}}(k W h)=2.725 \cdot 10^{-3} Q_{i} P_{\min I_{i}} \Delta t
$$

where:

$P_{\min I_{i}}$ is the minimum pressure of service of an irrigation point required to ensure the irrigation water evenly. The units are meter water column ( $\mathrm{m}$ w.c.).

- Theoretical Available Energy $\left(E_{T A i}\right)$ : it is the available energy for recovery in a hydrant or line. The recovery coefficient in a hydrant or line $\left(\mathrm{C}_{\mathrm{RT}}\right)$ depends on losses existent between the hydrant (or pipeline) and the most disadvantageous consumption node. It is equal to the sum of the theoretical energy recoverable plus the theoretical energy unrecoverable $\left(\mathrm{E}_{\mathrm{NRT}}\right)$. The value of this energy for a particular time duration, is defined as:

$$
E_{T A_{i}}(k W h)=2.725 \cdot 10^{-3} Q_{i}\left(P_{i}-P_{\text {min }_{i}}\right) \Delta t
$$

- Theoretical Recoverable Energy $\left(E_{T R i}\right)$ : it is the maximum theoretical recoverable energy in an irrigation point, hydrant or line of the network, ensuring at downstream the minimum pressure of irrigation. 


$$
E_{T R_{i}}(k W h)=2.725 \cdot 10^{-3} Q_{i}\left(P_{i}-\max \left(P_{\min _{i}} ; P_{\min I_{i}}\right)\right) \Delta t=2.725 \cdot 10^{-3} Q_{i} H_{i} \Delta t
$$

where

$H_{i}$ is the value of head in irrigation point, hydrant or line (m w.c.), obtained as:

$$
\boldsymbol{H}_{\boldsymbol{i}}=P_{i}-\max \left(P_{\min _{i}} ; P_{\min I_{i}}\right)
$$

- $\quad$ Theoretical unrecoverable Energy $\left(E_{N T R i}\right)$ : it is the energy in a hydrant or line on the network that cannot be recovered. This energy is necessary to assume the losses from the line or hydrant to the more unfavorable irrigation point.

$$
E_{N T R_{i}}=E_{T A_{i}}-E_{T R_{i}}
$$

- $\quad$ Recovery coefficient in hydrant or line $\left(C_{R T i}\right)$ : it is the quotient between $\mathrm{E}_{\mathrm{TRi}}$ and $\mathrm{E}_{\mathrm{TAi}}$ in an irrigation point, hydrant or line of the network. It represents the proportion of recovery energy over available energy.

$$
C_{R T_{i}}=\frac{E_{T R i}}{E_{T A i}}
$$

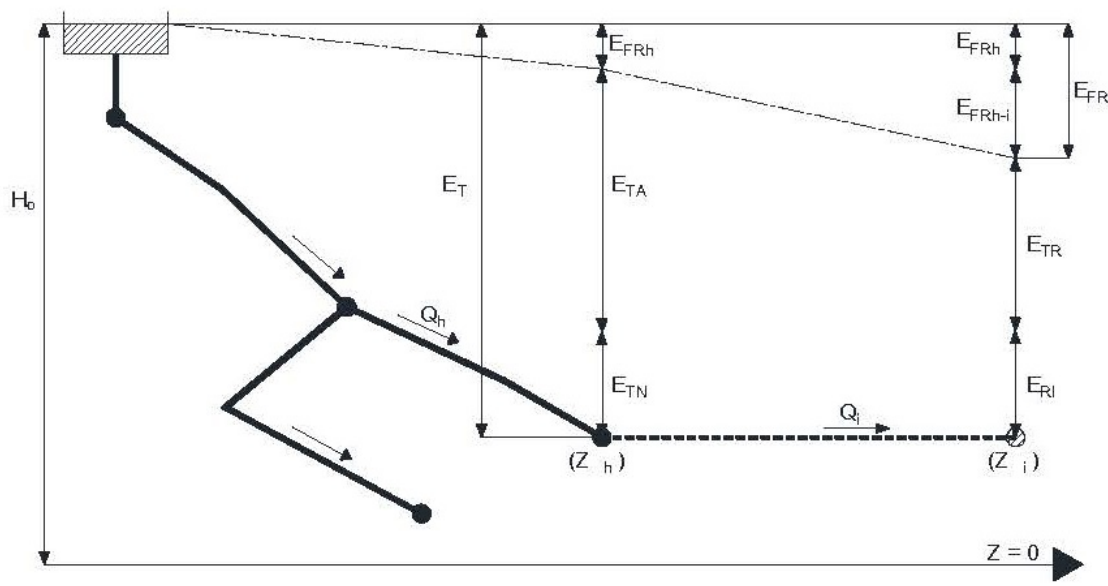

Figure 4. Scheme of hydraulic energies grade line.

$Q_{h}$ (Figure 4 ) is the flow circulating in a line or consumed by a hydrant $\left(\mathrm{m}^{3} / \mathrm{s}\right), z_{h}$ is the geometry level above reference plane of the line or hydrant. $H_{0}$ is the piezometric height of the reservoir that supplies the network. The units are meter water column (m w.c.). If reservoir is open, $H_{0}$ is equal to $z_{0}$.

When Equation (5) is applied in a point of the network, it is defined by Equation (15):

$$
E_{T i}=E_{F R i}+E_{R I i}+E_{T R i}
$$

When all irrigation points are considered $\left(z_{i}\right.$ in Figure 4$)$, the annual balance of energy is defined by Equation (16):

$$
\sum_{i=1}^{n} E_{T i}=\sum_{i=1}^{n}\left(E_{F R i}+E_{R I i}+E_{T R i}\right)
$$

In the case of lines and hydrants $\left(z_{h}\right.$ in Figure 4$)$, the annual balance of energy is defined by Equation (17):

$$
E_{T}=E_{F R h}+E_{T A}+E_{T N}=E_{F R h}+E_{R I}+E_{T R}+E_{N T R}
$$


The energy footprint of water and the theoretical recoverable energy are crucial for the energy balance. The energy footprint on the network distribution can be obtained along the year and compared with average values analyzed in other distribution systems. Some of these values are: $0.31 \mathrm{kWh} / \mathrm{m}^{3}$ in injected irrigation network [36], 0.18-0.32 $\mathrm{kWh} / \mathrm{m}^{3}$ according to California Energy Commission [37], $0.081 \mathrm{kWh} / \mathrm{m}^{3}$ in Bangkok, $0.5 \mathrm{kWh} / \mathrm{m}^{3}$ in Delhi and $0.13 \mathrm{kWh} / \mathrm{m}^{3}$ in Tokyo [38].

Regarding the theoretical recoverable energy in a network, it mainly depends on the orography of the irrigation area. The networks with larger gradients between the supply and the consumption points have greater possibility to recover energy, if the appropriate machine is selected. The energy recovery can be analyzed in different parts of the network:

i) In plot of cultivation-in this case, the private user needs to reduce pressure down to $30 \mathrm{~m}$ w.c. to carry out drip irrigation. Generally, the user installs a pressure reducer to dissipate the excess energy. This element can be replaced by a pico-turbine to generate energy for self-consumption. This energy can be used in remote-control system, cleaning of filters, lighting and others similar consumptions.

ii) In the hydrant pipe-when the hydrant supplies to flat topography, reduction of pressure can be done. In an operating network, this reduction is carried out with a pressure reducing valve. This recovery could potentially be done if a suitable turbine could be installed.

iii) In pipe branch-in networks with large extension and irregular orography, some parts of the network can achieve higher pressure than necessary, forcing pressure to be reduced on a pipe branch. Currently, this reduction is possible by using a reducing valve installed on this branch. These valves can be replaced by turbines or pumps as turbines (PAT) [14] depending on the system characteristics to increase the energy efficiency of the network.

The presented methodology helps managers to estimate the theoretical recoverable energy in irrigation points, hydrants and branches (pipelines). According to Spadaro et al. [39], this recovery can contribute with a theoretical average reduction of greenhouse gases emission between 582 and $877 \mathrm{gCO}_{2} / \mathrm{kWh}$ when compared to non-renewable energy solutions (e.g., coal and gas) and $1150 \mathrm{gCO}_{2} / \mathrm{kWh}$ when compared to emissions of fossil fuel [40]. However, this reduction will depend on the water source (groundwater, superficial or residual water) and distribution (gravity or pumped) [41]. Future research should try to integrate all applications together (supply, irrigation and wastewater for better water management) in a strategy to improve system efficiency, thus reducing greenhouse gases [42].

The viability of these installations is subject to economic evaluation (incomes vs. costs). Zema et al. [43] proposed a simple method to evaluate the economic feasibility of micro-hydropower plants in irrigations systems. In preliminary studies, these methods are good indicators for taking decisions to develop more detailed projects. These decisions are focused on the selection of machine efficiency, temporal distribution of energy produced and investment analyses. Similarly, Castro [44] proposed the period simple return (PSR) and energy index (EI) as indicators of investment viability. These sorts of installations are viable if the PSR is less than six years and the energy index smaller than $0.6 € / \mathrm{kWh}$. PSR and EI are defined by the following equations:

$$
\begin{gathered}
P S R=\frac{I C}{I-C} \\
I=P_{E} E \eta \\
C=C_{0} E \eta \\
E I=\frac{I C}{E}
\end{gathered}
$$


where: IC is the investment cost $(€) ; C$ is the annual operating cost $\left(€ /\right.$ year); $C_{0}$ is the unit operating cost $(€ / \mathrm{kWh}) ; I$ is the annual income (€/year); $P_{E}$ is the energy price $(€ / \mathrm{kWh}) ; E$ is the theoretical energy recovery by the turbine ( $\mathrm{kWh} /$ year) and $\boldsymbol{\eta}$ is the machine efficiency.

The investment cost using PAT is 50\% lower than the cost of traditional turbines [45]. Carravetta et al. [20] estimated IC of $545 € / \mathrm{kW}$ if the machine is electrically regulated. Incomes depend on generated energy, which depends on the price of energy, recovery energy and the efficiency of the machine. Based on the specific speed, expert literature indicates that efficiency varies between $50 \%$ and $60 \%[20,46]$. Castro [44] established a sales price $\left(P_{E}\right)$ of $0.0842 € / \mathrm{kWh}$ and $\mathrm{C}_{0}$ of $0.0145 € / \mathrm{kW}$. These solutions, due to the smaller cost of PATs, present a lower payback period.

\section{Case Study}

\subsection{Description}

In order to apply the developed methodology, a drip irrigation network located in Vallada (Valencia, Spain) is proposed (Figure 5). The network covers 290.2 hectares, with water coming from a well. The main crop is citrus, although there is a small area of olive trees. The water is accumulated in a reservoir with a $7000 \mathrm{~m}^{3}$ capacity. The topography varies between 378 and $248 \mathrm{~m}$ above sea level. The pond is located sufficiently high ( $399 \mathrm{~m}$ above sea level) to ensure the minimum pressure of $30 \mathrm{~m}$ w.c. in all irrigation points.

The pipelines of the network are built on asbestos cement pipes (diameters between 300 and $500 \mathrm{~mm}$ ), polyvinyl chloride (diameters between 250 and $125 \mathrm{~mm}$ ) and ductile iron (diameter of $150 \mathrm{~mm}$ ). The installation has seventy multiuser hydrants. A manifold is installed in each hydrant to connect pipes of polyethylene with irrigation points. Inside the hydrant, meters are placed to read the consumption volume.

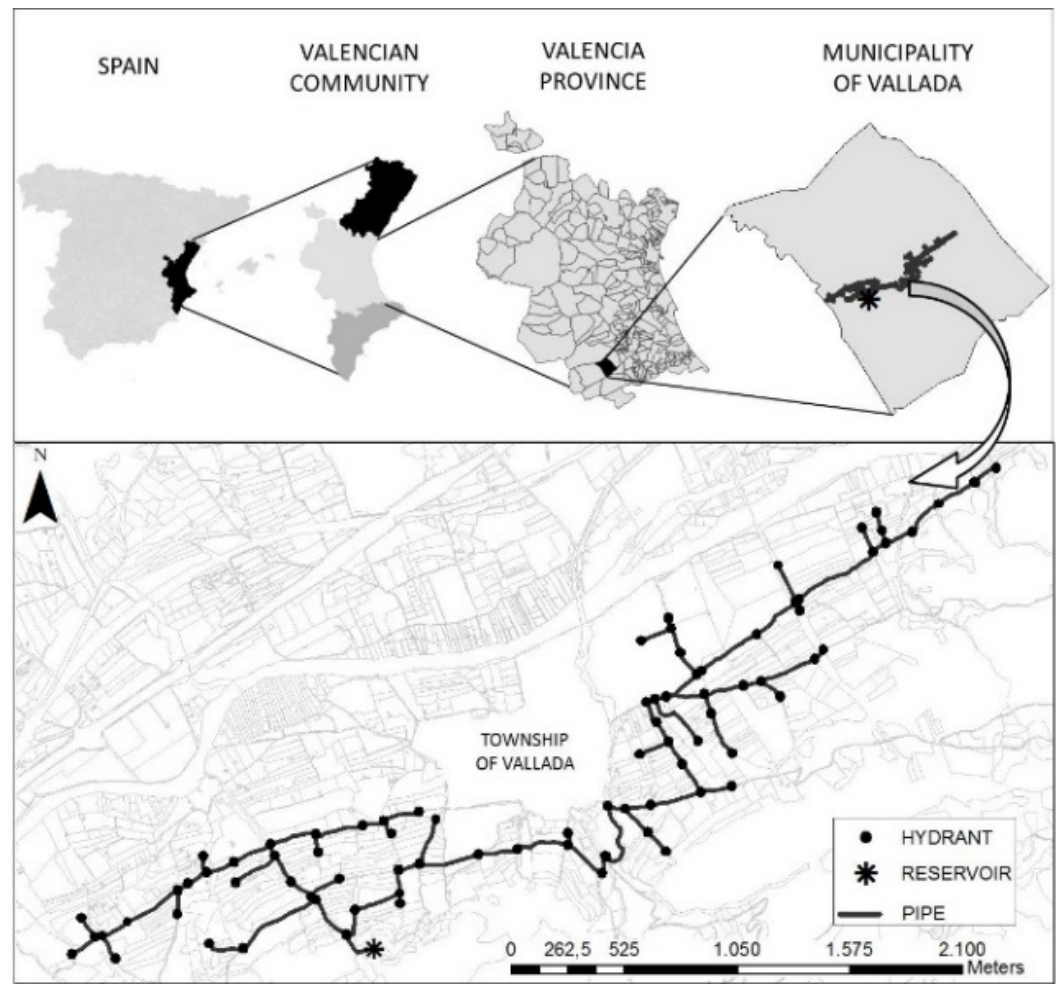

Figure 5. Study area in Vallada case study network.

The next steps are necessary to apply the proposed methodology: 
a) To make use of records of the water metered in the irrigation points. There are records since 2003 (year that network began to operate). In each plot, registers were taken quarterly corresponding to the months of March, June, September and December.

b) To calculate the flow design (water requirements) for each of the considered plot, according to the crop and characteristics of the irrigation installation (distance between drippers and type). The number of sectors is established depending on the area of plots. This has allowed an allocation of irrigation according to the existing installation (Figure 1).

c) To perform interviews of users and operating staff for estimating farmer habits. The type of irrigation management at the annual, monthly, weekly and daily levels has been analyzed in this questionnaire. Based on these interviews, different consumption patterns have been established. These patterns take in to account the irrigation habits of farmers: weekly trend, maximum days between irrigations and irrigation duration (Inputs 2, 3 and 4 in Figure 1).

\subsection{Methodology}

\subsubsection{Historical Consumption Data and Probability Function}

Based on the total consumption provided by the entity, an average consumption of $3189 \mathrm{~m}^{3} / \mathrm{ha}$ has been estimated. Therefore, the annual average consumption is $925,427 \mathrm{~m}^{3}$ in the time series studied 2003-2014 (Figure 6).

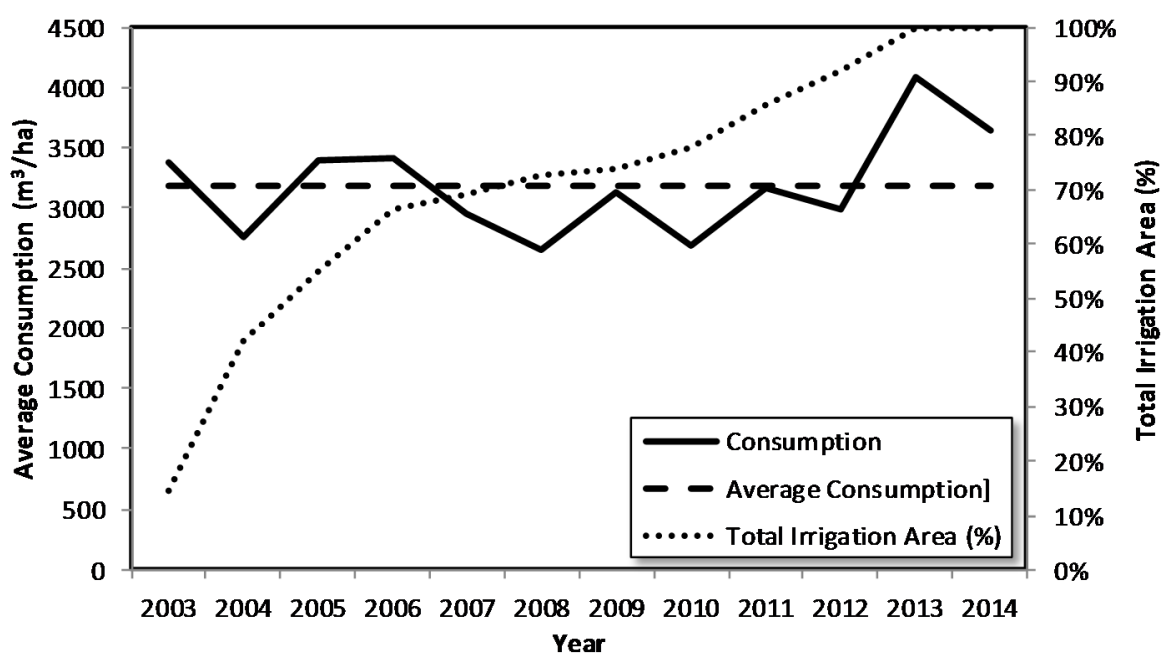

Figure 6. Measured Annual Consumption in Vallada case study network.

The next steps allow establishing consumption patterns:

1. The annual consumption is estimated for each irrigation point, grouping them in terms of similar consumptions. This classification has provided the distribution presented in Figure 7.

2. In order to determine the distribution of daily consumption, specific weights for crops of citrus and olive needs to be considered, according to the registered consumptions. The monthly pattern of irrigation needs has been set taking into account consumer groups (Figure 7). On the one hand, the irrigation points with consumptions lower than $3584 \mathrm{~m}^{3} /$ ha have been assigned the patterns of consumption under the name "Crop of Olive" (Figure 8). On the other hand, the irrigation points with consumptions higher than $4480 \mathrm{~m}^{3}$ / ha have been assigned the patterns of consumption under the name "Crop of Citrus" (Figure 8). 


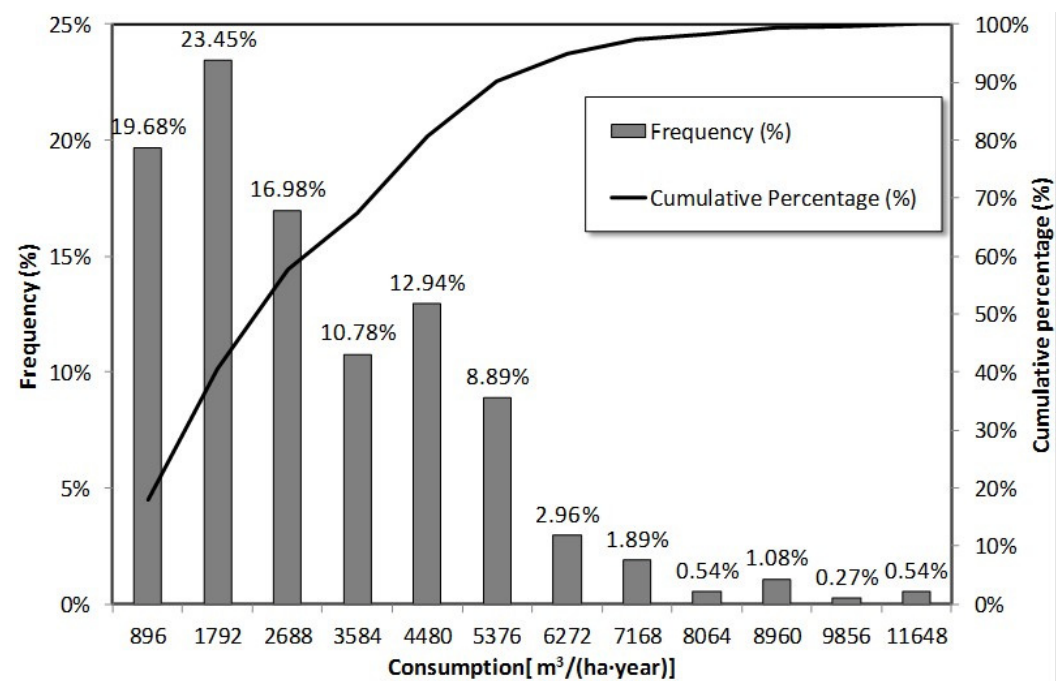

Figure 7. Distribution of annual consumptions in Vallada case study.

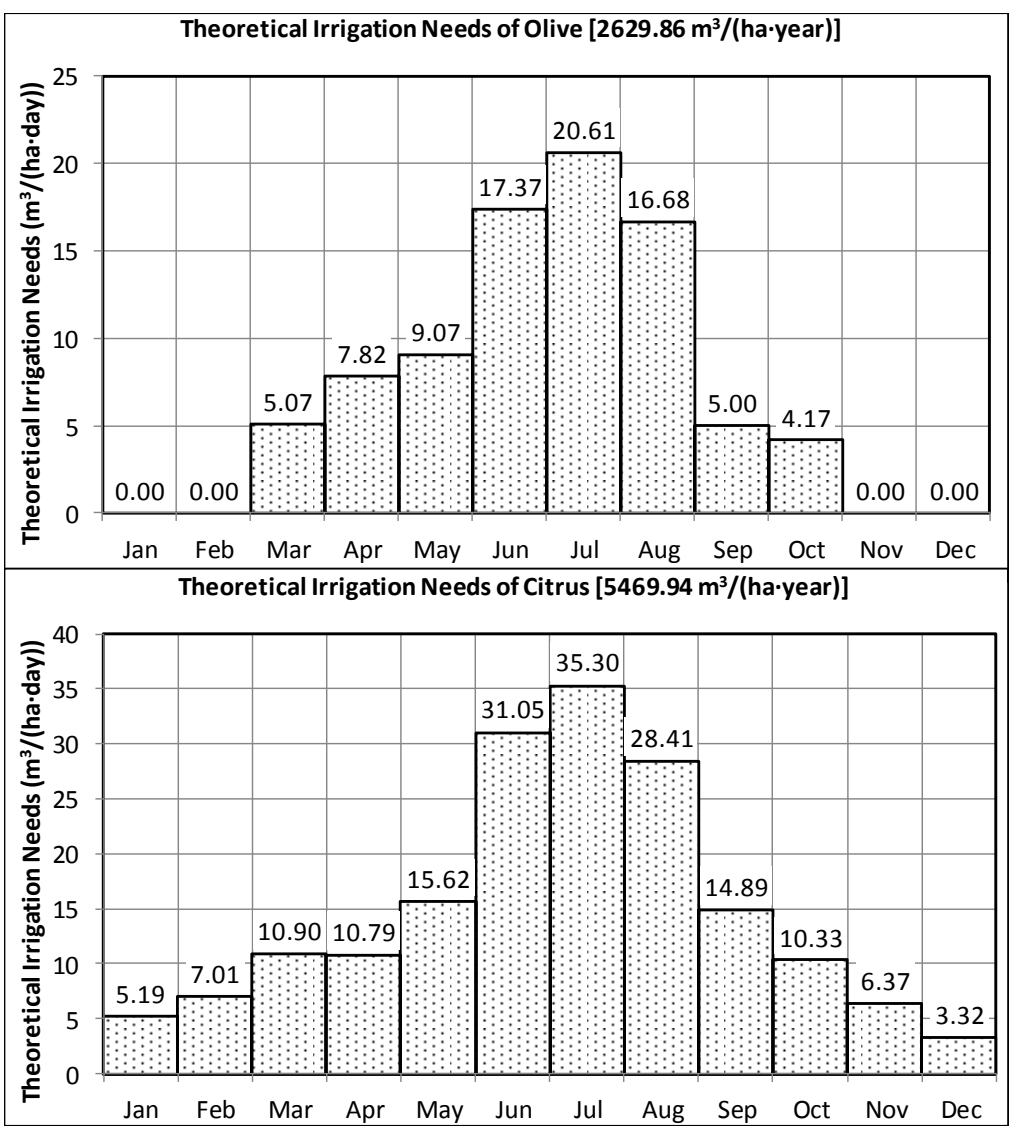

Figure 8. Pattern of irrigation needs: Top-Crop of olive. Bottom-Crop of citrus.

\subsubsection{Pattern of Irrigation Habits}

Habit patterns of farmers obtained by interviews, are defined as follows:

1. Analyzing the information obtained from interviews, two trends of irrigations have been depicted. Small farmers avoid Sunday as irrigation day and Saturday appears with double preference than the rest of the days (Figure 9a). Big farmers also have double preference for Saturday, but do not avoid irrigation on Sunday (Figure 9b). 
2. Distribution of maximum days between irrigations: these patterns refer to the maximum interval between watering. Irrigation occurs every day during the months of higher consumption (May, June, July, August and September). In remaining months, the intervals of irrigation increase, being not a clear and well-defined pattern for all farmers. Each farmer chooses the interval according to different factors (e.g., rain, availability and soil properties). Based on the results of the interviews, four distributions have been defined. According to the results of the requested data for farmer habits across surveys, patterns have been assigned. Pattern I has been assigned approximately to $40 \%$ of the irrigation points, pattern II to $20 \%$, pattern III to $20 \%$ and pattern IV to the other $20 \%$. This assignment has been carried out randomly (Figure 10).

3. Patterns of irrigation duration: based on the requested information four distributions have been proposed. Again, pattern I has been assigned approximately to $40 \%$ of the irrigation points, pattern II to $20 \%$, pattern III to $20 \%$ and pattern IV to other $20 \%$. This assignment has been carried out randomly (Figure 11).

4. Distribution of irrigation start probability: farmers tend to irrigate in certain particular hours of the day. This aspect is considered in this methodology by using the patterns for the probability of starting irrigation in the different schedules. The watering schedule between 10 A.M. and 4 P.M. is chosen in the months of January, February, March, April, October, November and December. However, farmers irrigate in different light hours in summer months to avoid warmer hours and night. Therefore, three patterns have been developed to define the probability (see Figure 1, step 4).

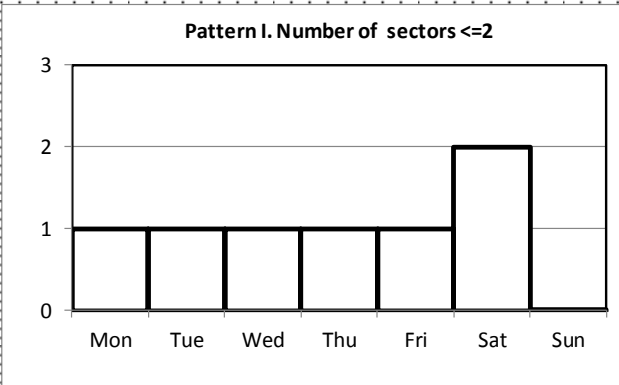

(a)

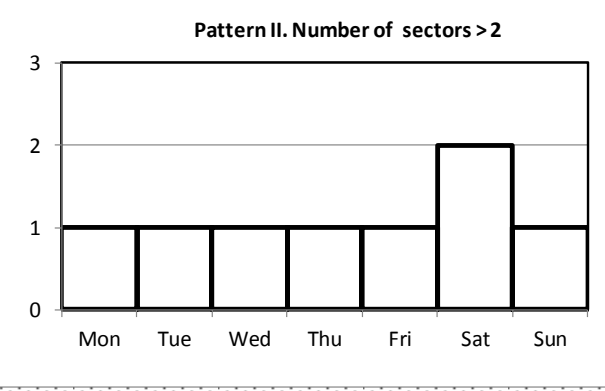

(b)

Figure 9. Weekly trend of irrigation pattern according to the number of sectors in the plot areas.

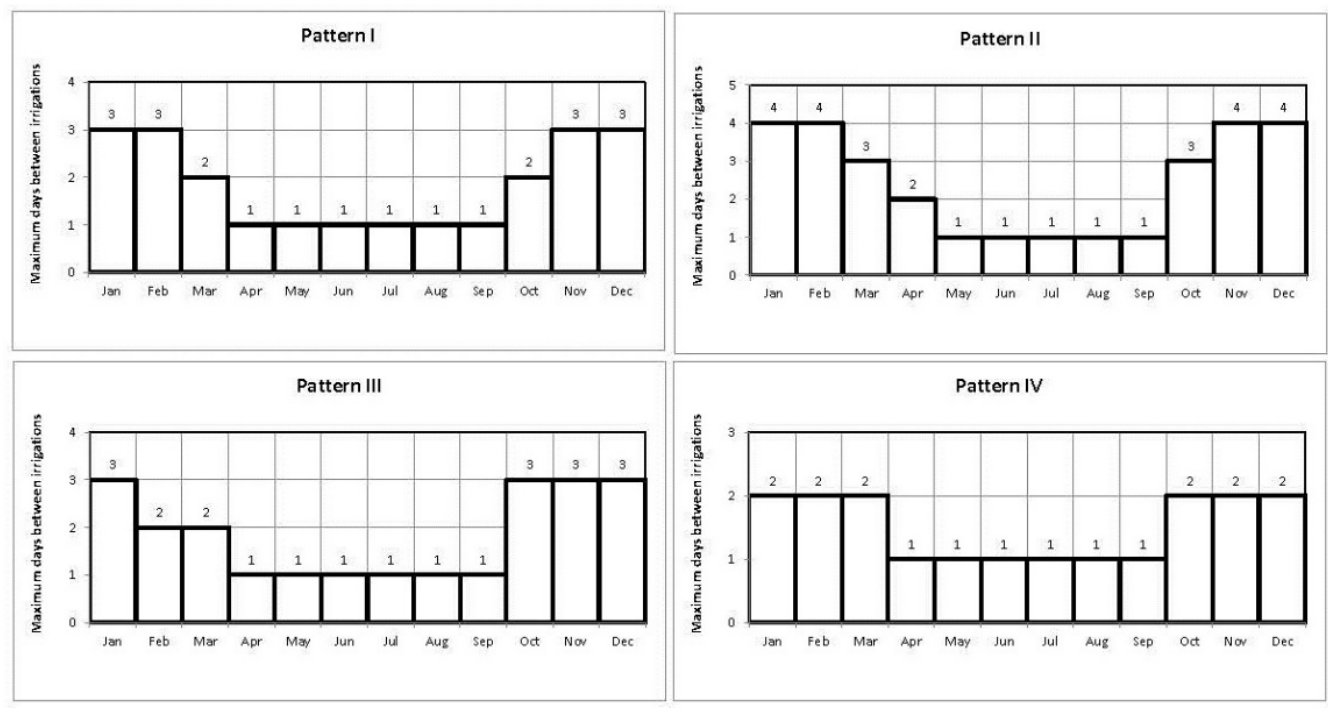

Figure 10. Patterns of maximum days between irrigations. 



Figure 11. Patterns of irrigation duration.

A first pattern is assigned to the winter months from October to April and considers that the irrigation starts between 8 A.M. and 6 P.M. A second pattern is assigned to the summer months, from May to September, where the irrigation avoids hours of day with higher temperatures. The watering schedule starts between 4 A.M. and 12 P.M. and from 6 P.M. to 12 A.M. Finally, a third pattern function is defined for irrigating plots with more of two sectors, at any time of the day along the year.

\section{Results}

\subsection{Basic Characteristics}

Following the methodology, an analysis for flows and pressures is necessary for energy consideration in the network based on hydraulic simulations. These simulations have been run with the software EPANET.

The model of the network developed by means of the software EPANET, has been run for each day along one year. In this case, these calculations have been repeated 20, 40 and 60 times with different scenarios represented. Nevertheless, comparing these simulations, the variability obtained when the flow in the main line is compared to the average flow is smaller than $5 \%$. As this deviation remains similar, no more repetitions are considered.

This methodology has been calibrated in other networks by the authors. The calibration has been performed with measured flow every five minutes. The results have been satisfactory with Nash-Sutcliffe index upper to 0.40 , root relative squared mean error below 0.7 and percent bias below $5 \%$, as indicated in [47].

Figures 12 and 13 depict the topology of the network to be considered and analyzed in further sections. 


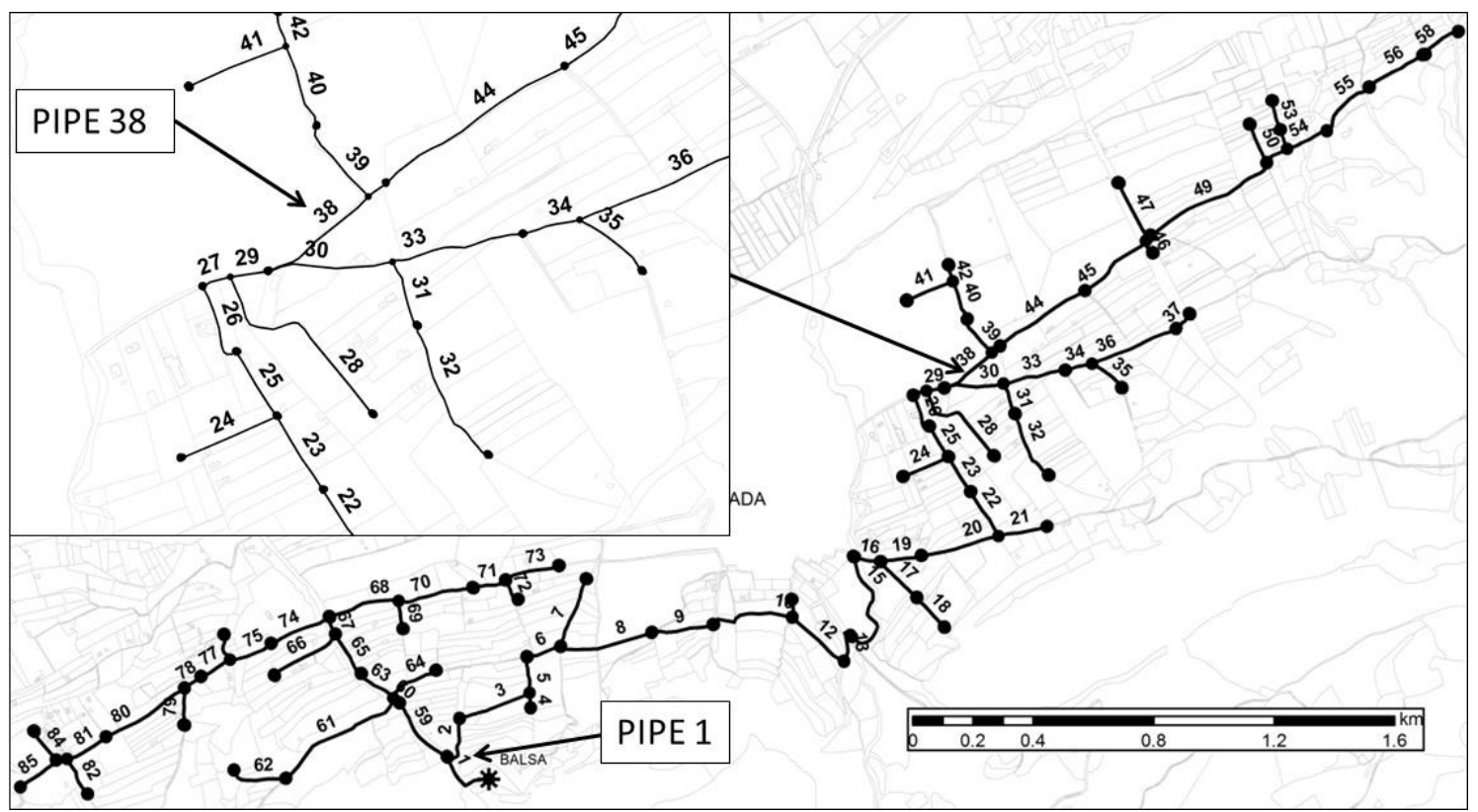

Figure 12. Identification of pipes in the irrigation network.

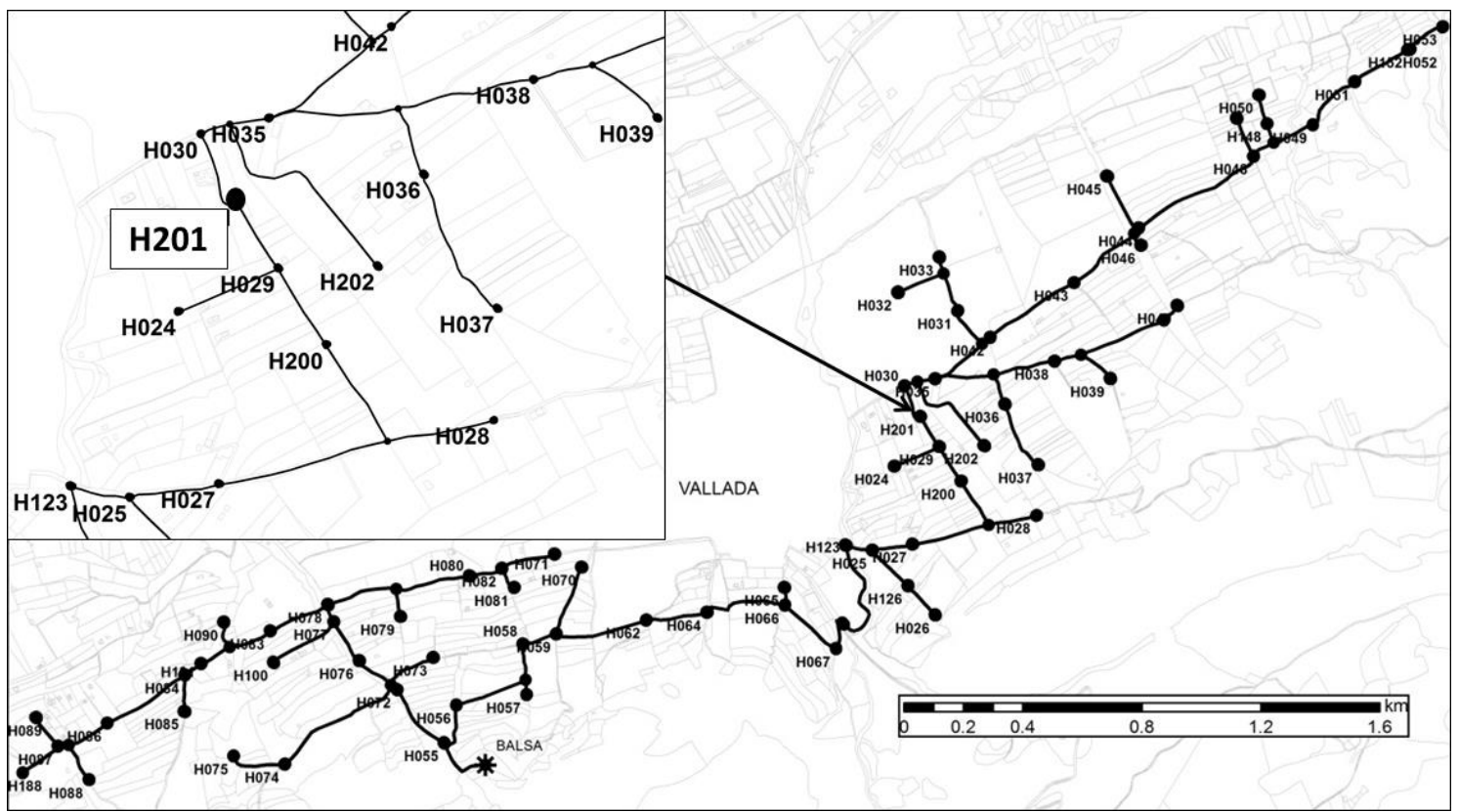

Figure 13. Identification of hydrants in the irrigation network.

\subsection{Flows in the Network}

Flow and pressure have been obtained along the time, based on the historical series of records registered between 2003 and 2014, in any line of the system, according to the irrigation trends. These time series of data collected in those 12 years (17,808 records), flow in the main line (see Figure 12, line 1) and hydrant 201 (see Figure 13, H201) are depicted in Figure 14. 


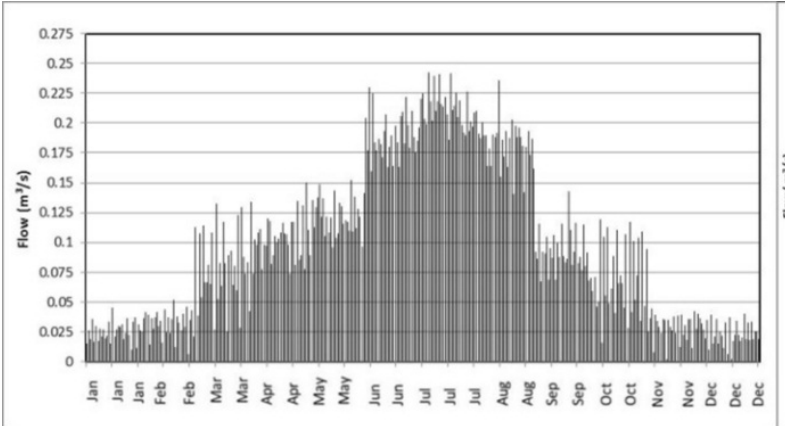

(a)

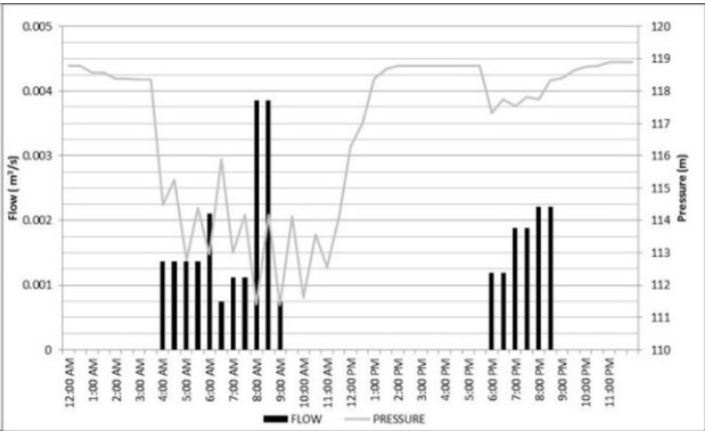

(b)

Figure 14. Flow in the main line (pipe 1) along the year (a); Flow and pressure variation in the hydrant (H201) over time (b).

The frequency histogram (Figure 15) displays the large variability of flows along the year. Hence, irrigation networks behave in a different way than drinking systems: monthly seasonal ratios range between 0.8 and 1.2 in drinking networks (except for touristic cities) and its variability of flows during the day varies between 0.7 and 1.5 of the average value. Opposite to this, the flow seasonality factor in irrigation systems is much larger than in drinking systems. In the case of citrus, seasonality factor varies between 0.14 and 2.36 times relative to the annual average consumption volume. According to this, the estimated variability in this network case study ranges between 0.1 and 2.54 times the average flow.

Additionally, there is a very high frequency of very low flows (Figure 15). Flows below $0.05 \mathrm{~m}^{3} / \mathrm{s}$ ( $25 \%$ of the maximum flow rate) arise up to $80 \%$ times in the main line of the network. These small flows will become of utmost importance to be used for energy recovery.

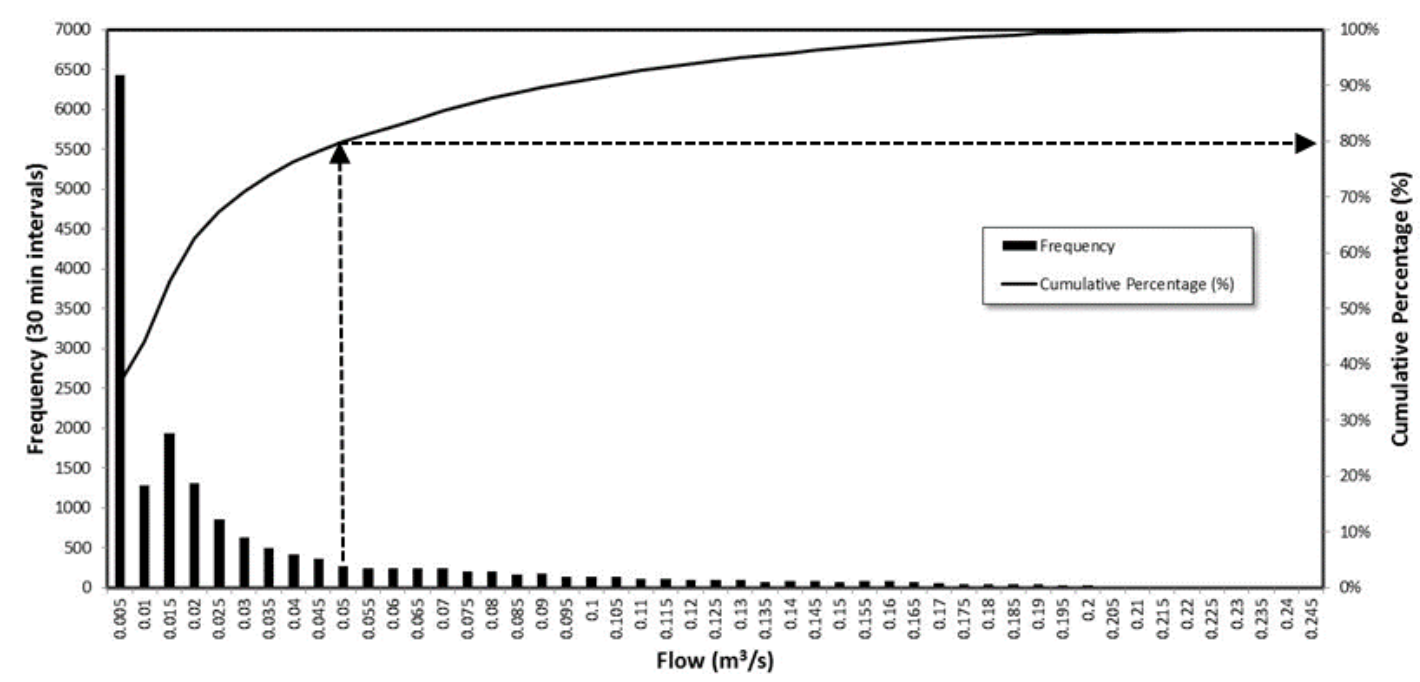

Figure 15. Histogram of flow in the main line.

\subsection{Water-Energy Nexus Estimation}

This section analyzes the estimation of energy dissipated in the network as a result of friction losses. Figure 16 shows the variation of the energy footprint based on time. The network is working $5943 \mathrm{~h}$ during of the year. Figure 16 shows the energy footprint during the distribution of flows in the water network. As shown in the histogram, $99.7 \%$ of the time the network has an energy footprint below $2 \mathrm{kWh} / \mathrm{m}^{3}$. The maximum value obtained is $2.87 \mathrm{kWh} / \mathrm{m}^{3}$ for a July day. However, $58.5 \%$ of the time the network has an energy footprint below $0.1 \mathrm{kWh} / \mathrm{m}^{3}$. 


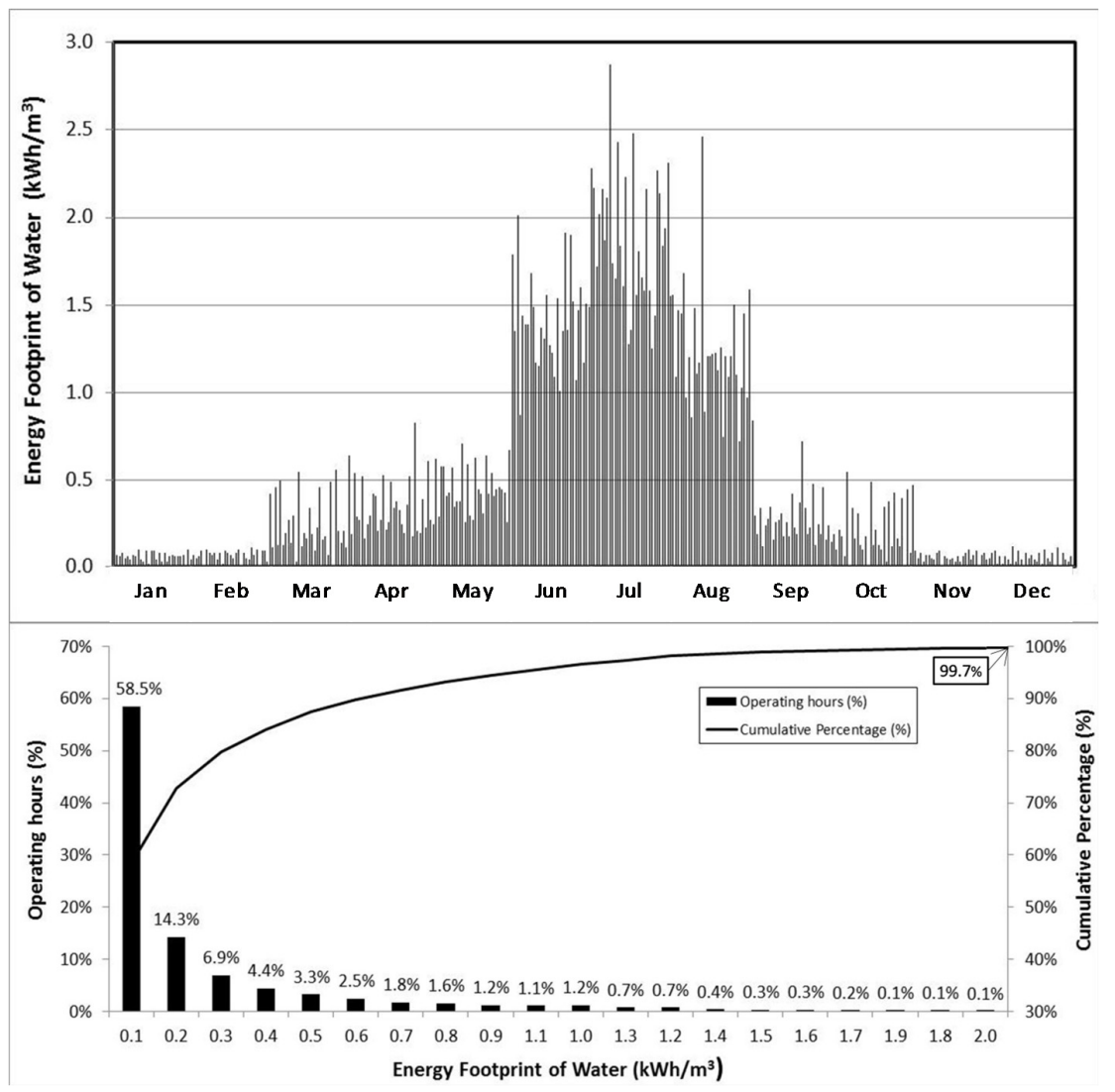

Figure 16. Network energy footprint of water.

\subsection{Theoretical Recoverable Energy}

If the results are analyzed in irrigation points, the total theoretical recoverable energy is 188.23 MWh/year (i.e., $68.7 \%$ of the total energy supplied to the network). In these nodes, the theoretical coefficient of recovery $\left(C_{R T}\right)$ is equal to one, as $E_{R T}$ is equal to $E_{T A}$.

Figure 17 shows a detail of instantaneous power along data registered for the month of July for the analyzed time series, and the distribution of instant power frequencies over time for an irrigation point. In these points, the frequency at which the value of instantaneous power appears is practically constant because the consumption flow is uniform and only pressure varies due to the use of pressure-compensating drippers.

As an example, in irrigation point 303, the annual operating time is $2957 \mathrm{~h}$. The instantaneous power oscillates between $9.96 \mathrm{~kW}$ and $11.64 \mathrm{~kW}$. The maximum power occurs $44.2 \%$ of time, and the theoretical total energy is $33.80 \mathrm{MWh}$ /year (Figure 17).

In the case of hydrants, the result is similar where the sum of the theoretical recoverable energy is 178.1 MWh/year. Figure 18 shows analogous results to those exposed in the irrigation points. Particularly, a maximum instantaneous power of $4.64 \mathrm{~kW}$ is achieved in hydrant $\mathrm{H} 201$, with an annual operating time of $1460 \mathrm{~h}$ and total energy of $1.59 \mathrm{MWh} /$ year. The average weighted coefficient of recovery in this hydrant is 0.68 (i.e., $9.68 \%$ of the total energy could be recovered if turbines had $100 \%$ efficiency). The maximum recovery occurs in the hydrant H045 with $16.12 \mathrm{MWh} /$ year, with a recovery rate of 0.83 (Figure 18).

The values of theoretical energy recoverable in all hydrants are detailed in Table 1, as well as their recovery coefficients. The theoretical maximum recoverable energy is obtained in hydrant $\mathrm{H} 042$ with a total energy of $33.73 \mathrm{MWh}$ /year, and a coefficient of recovery of 0.80 . The theoretical energy ranges between 0.01 (H056) and 33.73 MWh/year. The recovery coefficient ranges between 0.14 (H055) and 0.84 (H053). The weighted average recovery coefficient is 0.75 . 



Figure 17. Potential Power in the irrigation point 303.
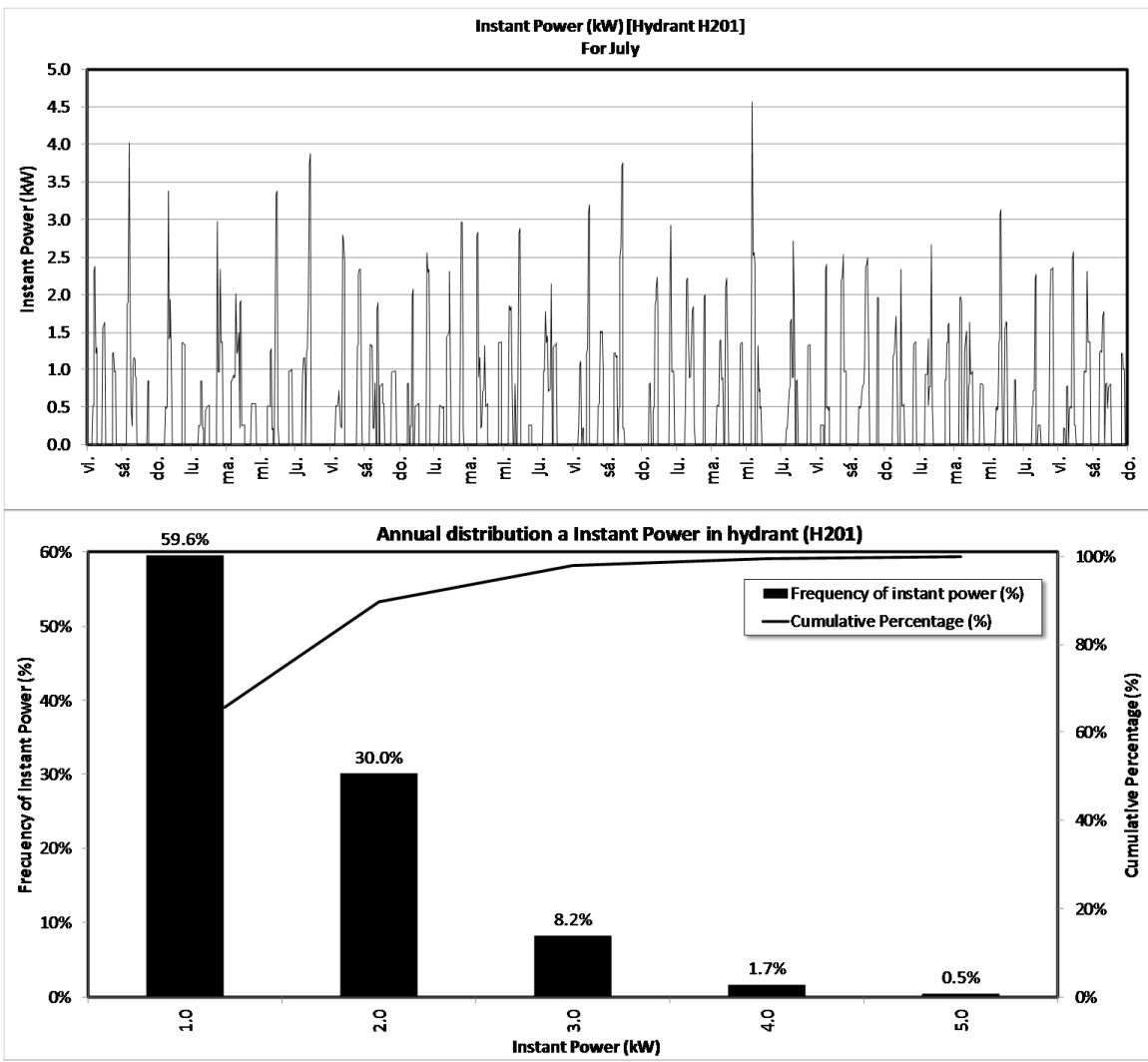

Figure 18. Potential Power in hydrant H201. 
Table 1. Theoretical energy recoverable in hydrants on the irrigation network.

\begin{tabular}{|c|c|c|c|c|c|}
\hline \multirow{2}{*}{ HYDRANT } & $E_{R T}$ & \multirow{2}{*}{$\mathrm{C}_{\mathrm{RT}}$} & \multirow{2}{*}{ HYDRANT } & $E_{R T}$ & \multirow{2}{*}{$C_{R T}$} \\
\hline & MWh/Year & & & MWh/Year & \\
\hline H024 & 1.99 & 0.66 & H065 & 0.80 & 0.63 \\
\hline H025 & 1.56 & 0.76 & H066 & 0.13 & 0.57 \\
\hline H026 & 0.48 & 0.59 & H067 & 0.22 & 0.53 \\
\hline H027 & 1.92 & 0.67 & H070 & 1.40 & 0.69 \\
\hline H028 & 0.12 & 0.46 & H071 & 0.40 & 0.72 \\
\hline H029 & 2.27 & 0.72 & H072 & 0.28 & 0.35 \\
\hline H030 & 0.77 & 0.80 & H073 & 0.22 & 0.45 \\
\hline H031 & 1.36 & 0.81 & H074 & 0.64 & 0.40 \\
\hline H032 & 3.94 & 0.73 & H075 & 0.31 & 0.54 \\
\hline H033 & 4.19 & 0.81 & H076 & 1.34 & 0.55 \\
\hline H035 & 3.57 & 0.79 & H077 & 0.52 & 0.64 \\
\hline H036 & 2.50 & 0.76 & H078 & 3.68 & 0.69 \\
\hline H037 & 1.12 & 0.69 & H079 & 0.76 & 0.53 \\
\hline H038 & 3.54 & 0.71 & H080 & 1.41 & 0.66 \\
\hline H039 & 0.64 & 0.69 & H081 & 0.40 & 0.72 \\
\hline H040 & 3.57 & 0.65 & H082 & 1.28 & 0.71 \\
\hline H042 & 33.73 & 0.80 & H083 & 0.87 & 0.72 \\
\hline H043 & 9.13 & 0.81 & H084 & 0.80 & 0.67 \\
\hline H044 & 5.60 & 0.78 & H085 & 1.50 & 0.58 \\
\hline H045 & 16.12 & 0.83 & H086 & 0.48 & 0.52 \\
\hline H046 & 5.14 & 0.72 & H087 & 0.27 & 0.58 \\
\hline H047 & 5.03 & 0.80 & H088 & 0.51 & 0.26 \\
\hline H048 & 13.37 & 0.80 & H089 & 0.73 & 0.59 \\
\hline H049 & 0.26 & 0.82 & H090 & 0.59 & 0.69 \\
\hline H050 & 1.93 & 0.77 & H100 & 0.89 & 0.65 \\
\hline H051 & 2.67 & 0.59 & H101 & 1.05 & 0.63 \\
\hline H052 & 0.86 & 0.77 & H123 & 1.78 & 0.79 \\
\hline H053 & 11.05 & 0.84 & H126 & 0.47 & 0.68 \\
\hline H055 & 0.04 & 0.14 & H140 & 0.73 & 0.74 \\
\hline H056 & 0.01 & 0.28 & H148 & 0.32 & 0.82 \\
\hline H057 & 0.55 & 0.26 & H152 & 2.47 & 0.72 \\
\hline H058 & 0.99 & 0.60 & H188 & 2.81 & 0.68 \\
\hline H059 & 0.46 & 0.61 & H200 & 1.35 & 0.77 \\
\hline H062 & 2.32 & 0.57 & H201 & 1.58 & 0.68 \\
\hline H064 & 0.22 & 0.28 & H2O2 & 2.08 & 0.76 \\
\hline
\end{tabular}

The line that presents the maximum recoverable energy is depicted in Figure 19 and Table 2. This condition is set on line 38, with maximum recoverable energy of $89.99 \mathrm{MWh} /$ year and an average weighted recovery rate of 0.64 . The maximum instantaneous power is $63.7 \mathrm{~kW}$. The histogram presented in Figure 19 shows that during $918 \mathrm{~h}$ of the operating time (17.1\%), the instantaneous power arises up to $10 \mathrm{~kW}$.

Table 2 shows that the maximum recoverable energy is obtained in line 38 with total energy of $89.99 \mathrm{MWh} /$ year and a coefficient of recovery 0.64 . The estimated energy $\left(E_{R T}\right)$ ranges between 0.12 (line 21) and $89.99 \mathrm{MWh}$ /year, the range of recovery coefficient can be found between 0.15 (line 74) and 0.84 (line 58) and the weighted average coefficient is 0.48 .

The pairs of flow, $Q_{i}$, and head, $H_{i}$, defined in Equation (11) for any point of the network are crucial to determine energetic aspects. With these data (flow and head), the estimated area of operation of the future selected machine could be determined. This cloud of point pairs is depicted in Figure 20 for an irrigation point, a hydrant and two of the lines with the maximum theoretical recoverable energy.

Figure 20 shows that not all lines have narrow operating point intervals. Line 59 has a large dispersion of operating points in the flow range. Similar circumstances occur in hydrant H201 with a wide range of flow, making the choice of a unique turbine difficult. In the case of recovery in 
irrigation points, the flow is constant with an interval of pressure according to the demand of the network. This becomes an additional advantage in which the performance of the chosen machine could be easily optimized.

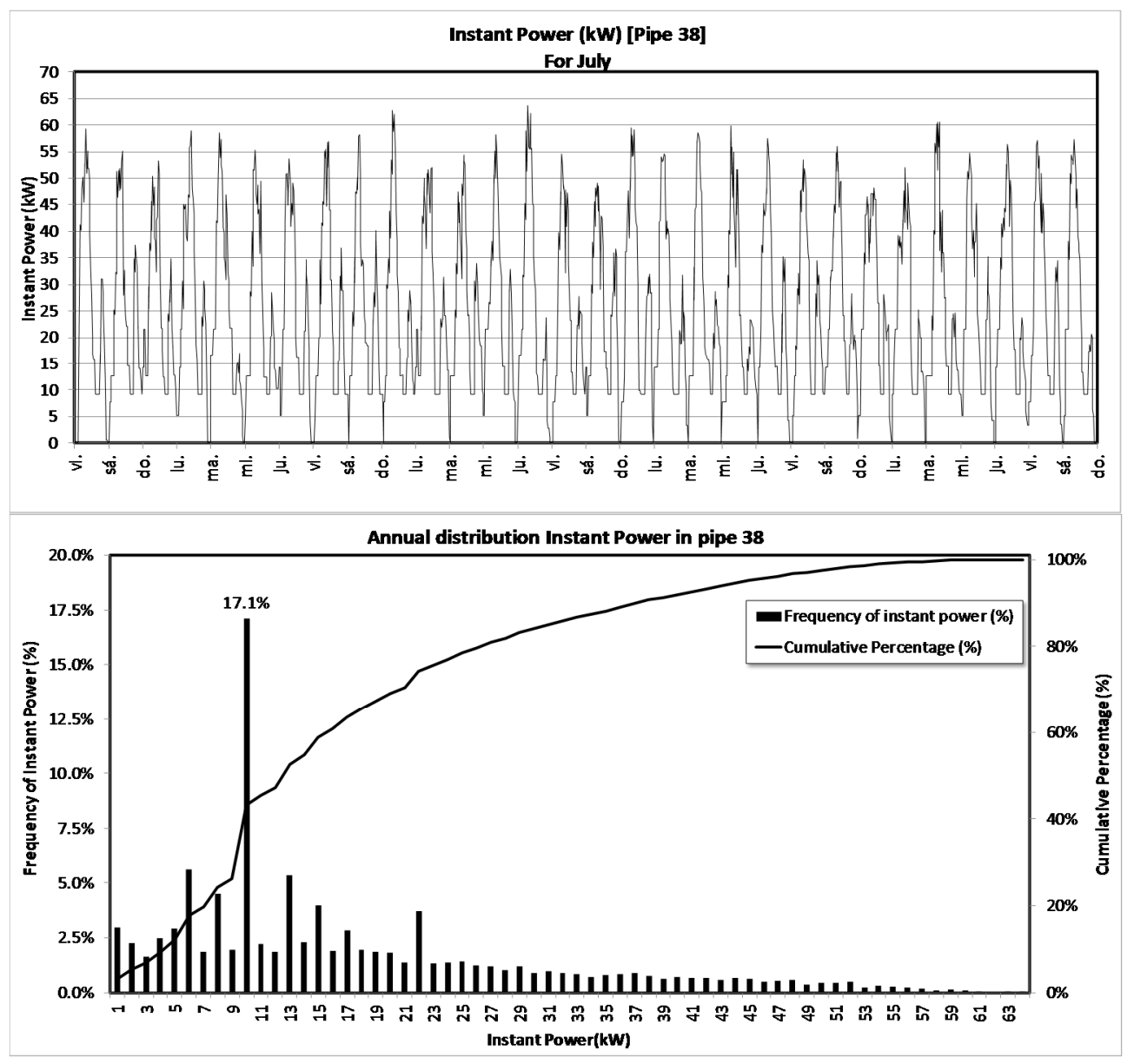

Figure 19. Potential Power in line 38.

Table 2. Estimated energy recoverable in lines on the irrigation network.

\begin{tabular}{cccccc}
\hline \multirow{2}{*}{ PIPE } & $E_{\boldsymbol{R} T}$ & \multirow{2}{*}{$\boldsymbol{C}_{\boldsymbol{R} T}$} & PIPE & $E_{\boldsymbol{R} T}$ & \multirow{2}{*}{$\mathrm{C}_{\mathbf{R T}}$} \\
\cline { 2 - 3 } & MWh/year & & & MWh/year & \\
\hline 1 & 4.29 & 0.16 & 44 & 55.58 & 0.64 \\
2 & 17.56 & 0.29 & 45 & 48.35 & 0.63 \\
3 & 18.64 & 0.23 & 46 & 5.14 & 0.72 \\
4 & 0.55 & 0.26 & 47 & 16.12 & 0.83 \\
5 & 26.83 & 0.26 & 48 & 32.61 & 0.62 \\
6 & 26.41 & 0.25 & 49 & 28.13 & 0.60 \\
7 & 1.40 & 0.69 & 50 & 5.03 & 0.80 \\
8 & 25.85 & 0.25 & 51 & 14.49 & 0.60 \\
9 & 24.84 & 0.29 & 52 & 2.24 & 0.81 \\
10 & 41.64 & 0.40 & 53 & 1.93 & 0.77 \\
11 & 0.80 & 0.63 & 54 & 12.88 & 0.58 \\
12 & 41.10 & 0.33 & 55 & 12.70 & 0.59 \\
13 & 40.96 & 0.28 & 56 & 12.62 & 0.72 \\
14 & 40.96 & 0.28 & 57 & 0.86 & 0.77 \\
15 & 40.96 & 0.25 & 58 & 11.05 & 0.84 \\
16 & 40.42 & 0.24 & 59 & 10.56 & 0.46 \\
\hline
\end{tabular}


Table 2. Cont

\begin{tabular}{|c|c|c|c|c|c|}
\hline \multirow{2}{*}{ PIPE } & $E_{R T}$ & \multirow{2}{*}{$C_{R T}$} & \multirow{2}{*}{ PIPE } & $E_{R T}$ & \multirow{2}{*}{$\mathrm{C}_{\mathrm{RT}}$} \\
\hline & MWh/year & & & MWh/year & \\
\hline 17 & 0.77 & 0.42 & 60 & 10.18 & 0.43 \\
\hline 18 & 0.48 & 0.59 & 61 & 0.85 & 0.39 \\
\hline 19 & 39.40 & 0.27 & 62 & 0.31 & 0.54 \\
\hline 20 & 38.64 & 0.35 & 63 & 5.79 & 0.21 \\
\hline 21 & 0.12 & 0.46 & 64 & 0.22 & 0.45 \\
\hline 22 & 83.51 & 0.57 & 65 & 5.27 & 0.17 \\
\hline 23 & 82.51 & 0.52 & 66 & 0.89 & 0.65 \\
\hline 24 & 1.99 & 0.66 & 67 & 4.90 & 0.16 \\
\hline 25 & 79.32 & 0.50 & 68 & 3.01 & 0.47 \\
\hline 26 & 78.15 & 0.50 & 69 & 0.76 & 0.53 \\
\hline 27 & 77.67 & 0.49 & 70 & 3.29 & 0.66 \\
\hline 28 & 2.08 & 0.76 & 71 & 1.96 & 0.66 \\
\hline 29 & 76.15 & 0.48 & 72 & 0.40 & 0.72 \\
\hline 30 & 9.88 & 0.48 & 73 & 0.40 & 0.72 \\
\hline 31 & 2.84 & 0.52 & 74 & 3.08 & 0.15 \\
\hline 32 & 1.12 & 0.69 & 75 & 2.90 & 0.16 \\
\hline 33 & 7.68 & 0.57 & 76 & 0.59 & 0.69 \\
\hline 34 & 4.83 & 0.59 & 77 & 2.78 & 0.16 \\
\hline 35 & 0.64 & 0.69 & 78 & 2.51 & 0.17 \\
\hline 36 & 4.20 & 0.64 & 79 & 1.50 & 0.58 \\
\hline 37 & 3.57 & 0.65 & 80 & 1.78 & 0.19 \\
\hline 38 & 89.99 & 0.64 & 81 & 1.60 & 0.21 \\
\hline 39 & 8.86 & 0.75 & 82 & 0.51 & 0.26 \\
\hline 40 & 7.59 & 0.72 & 83 & 2.98 & 0.59 \\
\hline 41 & 3.94 & 0.73 & 84 & 0.73 & 0.59 \\
\hline 42 & 4.19 & 0.81 & 85 & 2.81 & 0.68 \\
\hline 43 & 82.74 & 0.64 & - & - & - \\
\hline
\end{tabular}
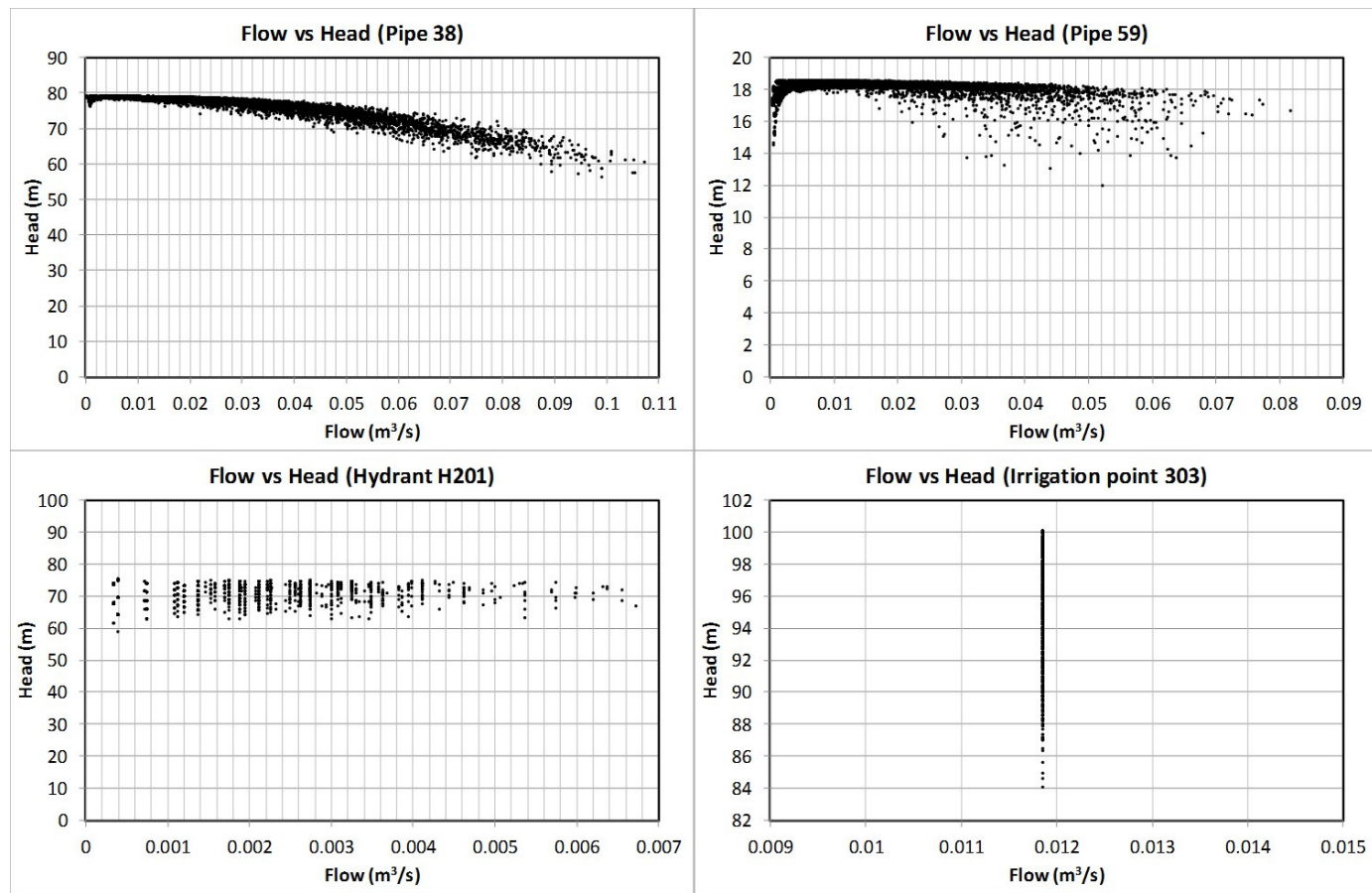

Figure 20. Representation of flow versus head for ideal turbine characteristics in irrigation point, hydrant and lines 38 and 55. 


\subsection{Global Energy Balance}

The global energy network analysis in this case study, shows that with a total of $274.00 \mathrm{MWh} /$ year of the network $\left(E_{T}\right)$, the energy dissipated by friction $\left(E_{F R}\right)$ is $11.25 \mathrm{MWh} /$ year $(4.10 \%)$, the energy required for irrigation $\left(E_{R I}\right)$, is $74.52 \mathrm{MWh}$ /year and the theoretical energy recoverable $\left(E_{T R}\right)$ is 188.23 MWh/year (considering the sum of total individual recovery in all irrigation points).

If total energy balance in hydrants is calculated, the distribution of energy in the network is defined by Figure 21. This graphic shows that in the case of carrying out energy recovery at all hydrants, theoretical energy recoverable would be $75.2 \mathrm{MWh} /$ year $(27.4 \%$ compared to the total energy $E_{T}$ ).

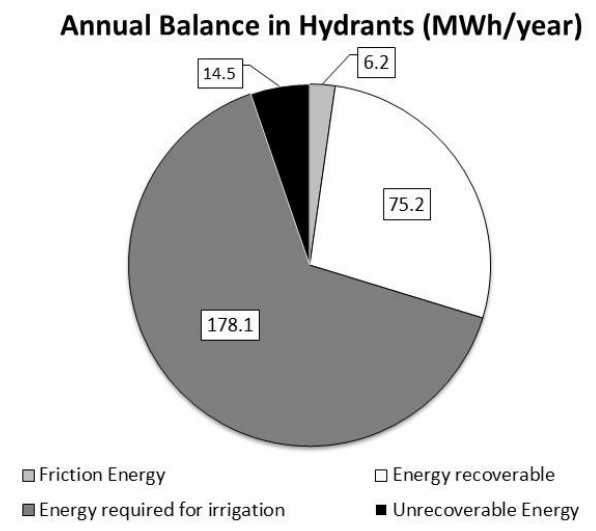

Figure 21. Annual Balance Energy in hydrants.

Finally, the virtual possibility of recovering all of the estimated energy in all irrigations points is $188.23 \mathrm{MWh}$ /year. In this case, the environmental impact versus generation with non-renewable resources (e.g., coal and gas) would be a theoretical reduction of $137.4 \mathrm{t}$ of $\mathrm{CO}_{2} /$ year or $216.2 \mathrm{t}$ of $\mathrm{CO}_{2} /$ year with fuels.

\subsection{Economic Feasibility}

In a first economical approach, the maximum theoretical recovery line is analyzed (line 38). The corresponding PAT proposed for line 38 would have a PSR value of 5.9 years and EI of $0.22 € / \mathrm{kWh}$ (Equations (18) and (21)). In this case, these results are established by considering a machine of $30 \mathrm{~kW}$ peak power with efficiency of $50 \%$ and the economic parameters defined in Section 2.2.

\section{Conclusions}

In this research, a methodology for quantifying the potential recovered energy for an average year in an irrigation network has been presented. Even nowadays, some irrigation networks do not have flowmeters. In these cases, a flow estimation method must be implemented: the flow is assigned to pipes along time depending on registered volumes, irrigation trends, and consumption patterns.

Once flows are known, the EPANET toolkit is used for estimating pressures in different scenarios along the year in order to determine pressure and energy balance for each point. Hence, it is possible to discriminate the energy needed for irrigation, friction head losses, non-recoverable energy, and potentially recoverable energy in any line or hydrant in a network.

The method was demonstrated as applied to a real case. Considering consumption records from 2003 to 2014, an irrigation network in Valencia (Spain) has been analyzed in order to determine the dissipated and recoverable energy, observing that the energy footprint achieves maximum values of $2.85 \mathrm{kWh} / \mathrm{m}^{3}$, being $79.7 \%$ of time under $0.3 \mathrm{kWh} / \mathrm{m}^{3}$. The potential recoverable energy, instant power, recovering coefficients relating total with recoverable energy and frequency histogram of power are studied for any irrigation point, hydrant or line. 
The maximum estimated potential recoverable energy sums to $188.23 \mathrm{MWh} /$ year considering all the consumption points, and $178.1 \mathrm{MWh} /$ year considering all the hydrants. If only one turbine were to be installed, the more convenient location is line 38, with a potential recovery of $89.99 \mathrm{MWh} /$ year.

Future works should be undertaken to analyze the performance of real turbines in lines in order to propose a method to optimize the selection of turbines and the technical and economic involvements of such installations in different irrigation networks.

Acknowledgments: This paper has been possible with the free collaboration of the "Comunidad de Regantes Virgen de Gracia". No additional funds have been received for this research. Authors thank the reviewers for their valuable comments, which have greatly contributed in the improvement of the document.

Author Contributions: All the authors have participated in any step of this research. Particularly a brief description is attached: The author Helena M. Ramos has contributed supervising the state of the art description, flow assignation and energy implications of the present study. The author Francisco Javier Sánchez-Romero has been involved in the conception of the methodology for flow assignation and computational programming for EPANET Toolkit. The author Modesto Pérez-Sánchez has analyzed the flow data for proposing the final flow distribution, has implemented the data for EPANET Toolkit and analyzed the results for energy determination. The author P. Amparo López-Jiménez has supervised the whole research and document and has been involved in final energy analysis of results and conclusions.

Conflicts of Interest: The authors declare no conflict of interest. The founding sponsors had no role in the design of the study; in the collection, analyses, or interpretation of data; in the writing of the manuscript, and in the decision to publish the results.

\section{References}

1. Kahil, M.; Albiac, J.; Dinar, A. Improving the performance of water policies: Evidence from drought in Spain. Water 2016, 8, 34. [CrossRef]

2. Llop, M.; Ponce-Alfonso, X. Water and agriculture in a Mediterranean region: The search for a sustainable water policy strategy. Water 2016, 8, 66. [CrossRef]

3. Corominas, J. Agua y Energía en el riego en la época de la sostenibilidad. Ing. Agua 2010, 17, $219-233$. [CrossRef]

4. Seoane, P.; Allué, R.; Postigo, M.J.; Cordón, M.A. Boletín Mensual de Estadística; Ministerio de Agricultura, Alimentación y Medio Ambiente: Madrid, Spain, 2013.

5. FAO. Agua Y Cultivos; FAO: Rome, Italy, 2002. Availiable online: http://www.fao.org/docrep/005/y3918s/ y3918s10.htm (accessed on 30 April 2016).

6. MAGRAMA. El riego Localizado Alcanza el 48.23\% de la Superficie Regada en España. Minist Agric Aliment y Medio Ambient. Available online: http:/ /www.magrama.gob.es/gl/prensa/noticias/el-riego-localizadoalcanza-el-4823--de-la-superficie-regada-en-espa\%C3\%B1a-/tcm7-312671-16 (accessed on 15 April 2016).

7. FAO. Superficie Equipada para el Riego. Available online: http://www.fao.org/nr/water/aquastat/ infographics/Irrigation_esp.pdf (accessed on 15 April 2016).

8. Pardo, M.A.; Manzano, J.; Cabrera, E.; García-Serra, J. Energy audit of irrigation networks. Biosyst. Eng. 2013, 115, 89-101. [CrossRef]

9. Coelho, B.; Andrade-Campos, A. Efficiency achievement in water supply systems-A review. Renew Sustain. Energy. Rev. 2014, 30, 59-84. [CrossRef]

10. Baki, S.; Makropoulos, C. Tools for energy footprint assessment in urban water systems. Procedia Eng. 2014, 89, 548-556. [CrossRef]

11. Okadera, T.; Chontanawat, J.; Gheewala, S.H. Water footprint for energy production and supply in Thailand. Energy 2014, 77, 49-56. [CrossRef]

12. Herath, I.; Deurer, M.; Horne, D.; Singh, R.; Clothier, B. The water footprint of hydroelectricity: A methodological comparison from a case study in New Zealand. J. Clean. Prod. 2011, 19, 1582-1589. [CrossRef]

13. Endo, A.; Burnett, K.; Orencio, P. Methods of the water-energy-food nexus. Water 2015, 7, 5806-5830. [CrossRef]

14. Mendoza-Grimón, V.; Hernández-Moreno, J.; Palacios-Díaz, M. Improving water use in fodder production. Water 2015, 7, 2612-2621. [CrossRef] 
15. Ramos, H.M.; Vieira, F.; Covas, D.I.C. Energy efficiency in a water supply system: Energy consumption and $\mathrm{CO}_{2}$ emission. Water Sci. Eng. 2010, 3, 331-340.

16. Choulot, A. Energy Recovery in Existing Infrastructures with Small Hydropower Plants; FP6 Project Shapes (Work Package 5-WP5); European Directorate for Transport and Energy: Brussels, Belgium, 2010.

17. Carravetta, A.; Fecarotta, O.; Del Giudice, G.; Ramos, H. Energy recovery in water systems by PATs: A comparisons among the different installation schemes. Procedia Eng. 2014, 70, 275-284. [CrossRef]

18. Carravetta, A.; Del Giudice, G.; Fecarotta, O.; Ramos, H. Pump as turbine (PAT) design in water distribution network by system effectiveness. Water 2013, 5, 1211-1225. [CrossRef]

19. Carravetta, A.; Del Giudice, G.; Fecarotta, O.; Ramos, H.M. Energy production in water distribution networks: A PAT design strategy. Water Resour. Manag. 2012, 26, 3947-3959. [CrossRef]

20. Carravetta, A.; Del Giudice, G.; Oreste, F.; Ramos, H. PAT design strategy for energy recovery in water distribution networks by electrical regulation. Energies 2013, 6, 411-424. [CrossRef]

21. Ramos, H.; Borga, A. Pumps as turbines: An unconventional solution to energy production. Urban Water 1999, 1, 261-263. [CrossRef]

22. Ramos, H.; Borga, A.; Simão, M. New design solutions for low-power energy production in water pipe systems. Water Sci. Eng. 2009, 2, 69-84.

23. Adhau, S.P.; Moharil, R.M.; Adhau, P.G. Mini-hydro power generation on existing irrigation projects: Case study of Indian sites. Renew. Sustain. Energy Rev. 2012, 16, 4785-4795. [CrossRef]

24. Butera, I.; Balestra, R. Estimation of the hydropower potential of irrigation networks. Renew. Sustain. Energy. Rev. 2015, 48, 140-151. [CrossRef]

25. Tilmant, A.; Goor, Q.; Pinte, D. Agricultural-to-hydropower water transfers: Sharing water and benefits in hydropower-irrigation systems. Hydrol. Earth Syst. Sci. 2009, 13, 1091-1101. [CrossRef]

26. Tarragó, E.F.; Ramos, H. Micro-Hydro Solutions in Alqueva Multipurpose Project (AMP) towards Water-Energy-Environmental Efficiency Improvements. Bachelor's Thesis, Universidade de Lisboa, Lisboa, Portugal, 2015.

27. Clément, R. Calcul des débits dans le réseaux d'irrigation fonctionnant á la demande. La Houille Blanche 1966, 5, 553-575. [CrossRef]

28. Mavropoulos, T.I. Sviluppo di una nuova formula per il calcolo delle portate di punta nelle reti irrigue con esercizio alla domanda. Riv. Irrig. Dren. 1997, 44, 27-35.

29. Maidment, D.R.; Hutchinson, P.D. Modeling water demands of irrigation projects. J. Irrig. Drain. Eng. 1983, 109, 405-418. [CrossRef]

30. Alandi, P.P.; Pérez, P.C.; Álvarez, J.F.O.; Hidalgo, M.; Martín-Benito, J.M.T. Pumping selection and regulation for water-distribution networks. J. Irrig. Drain. Eng. 1997, 131, 273-281. [CrossRef]

31. Aliod, R.; Eizaguerri, A.; Estrada, C. Dimensionado y análisis hidráulico de redes de distribución a presión en riego a la demanda: Aplicación del programa GESTAR. Riegos Dren. XXI 1997, 92, 22-38.

32. Pereira, L.S.; Teixeira, J.L. Modelling for Irrigation Delivery Scheduling: Simulation of Demand at Sector Level with Models ISAREG and IRRICEP; FAO: Rome, Italy, 1994.

33. Lamaddalena, N.; Sagardoy, J.A. Performance Analysis of On-Demand Pressurized Irrigation Systems; FAO: Roma, Italy, 2007.

34. Rossman, L.A. EPANET 2 User's Manual; U.S. Environmental Protection Agency (EPA): Cincinnati, OH, USA, 2000.

35. White, F.M. Fluid Mechanics, 6th ed.; McGrau-Hill: Madrid, Spain, 2008.

36. Cabrera, E.; Cobacho, R.; Soriano, J. Towards an energy labelling of pressurized water networks. Procedia Eng. 2014, 70, 209-217. [CrossRef]

37. Klein, G.; Krebs, M.; Hall, V.; O’Brien, T.; Blevins, B.B. California's Water-Energy Relationship; California Energy Commission: Sacramento, CA, USA, 2005.

38. Shrestha, S.; Dhakal, S.; Shrestha, A.; Kaneko, S.; Kansal, A. Water-Energy-Carbon Nexus in Cities: Cases from Bangkok, New Delhi, Tokyo. In Water Energy Food Nexus: International Cooperation and Technology Transfer; Asian Institute of Technology: Paris, France, 2015.

39. Spadaro, J.V.; Langlois, L.; Hamilton, B. Greenhouse Gas Emissions of Electricity Generation Chains: Assessing the Difference. IAEA Bull. 2000, 42, 19-28.

40. Weisser, D. A guide to life-cycle greenhouse gas (GHG) emissions from electric supply technologies. Energy 2007, 32, 1543-1559. [CrossRef] 
41. Arora, M.; Aye, L.; Malano, H.; Ngo, T. Water-energy-GHG emissions accounting for urban water supply: A case study on an urban redevelopment in Melbourne. Water Util. J. 2013, 6, 9-18.

42. Nair, S.; George, B.; Malano, H.M.; Arora, M.; Nawarathna, B. Water-energy-greenhouse gas nexus of urban water systems: Review of concepts, state-of-art and methods. Resour. Conserv. Recycl. 2014, 89, 1-10. [CrossRef]

43. Zema, D.A.; Nicotra, A.; Tamburino, V.; Zimbone, S.M. A simple method to evaluate the technical and economic feasibility of micro hydro power plants in existing irrigation systems. Renew. Energy 2016, 85, 498-506. [CrossRef]

44. Castro, A. Minicentrales Hidroeléctricas; Instituto para la Diversificación y Ahorro de la Energía: Madrid, Spain, 2006.

45. Elbatran, A.H.; Yaakob, O.B.; Ahmed, Y.M.; Shabara, H.M. Operation, performance and economic analysis of low head micro-hydropower turbines for rural and remote areas: A review. Renew. Sustain. Energy Rev. 2015, 43, 40-50. [CrossRef]

46. Derakhshan, S.; Nourbakhsh, A. Experimental study of characteristic curves of centrifugal pumps working as turbines in different specific speeds. Exp. Therm. Fluid Sci. 2008, 32, 800-807. [CrossRef]

47. Moriasi, D.N.; Arnold, J.G.; Van Liew, M.W.; Binger, R.L.; Harmel, R.D.; Veith, T.L. Model evaluation guidelines for systematic quantification of accuracy in watershed simulations. Trans. ASABE 2007, 50, 885-900. [CrossRef]

(C) 2016 by the authors; licensee MDPI, Basel, Switzerland. This article is an open access article distributed under the terms and conditions of the Creative Commons Attribution (CC-BY) license (http:/ / creativecommons.org/licenses/by/4.0/). 